\title{
Article \\ Optimal Parameter Estimation Methodology of Solid Oxide Fuel Cell Using Modern Optimization
}

\author{
Hesham Alhumade 1,2,*D, Ahmed Fathy ${ }^{3,4}$, Abdulrahim Al-Zahrani ${ }^{1}$, Muhyaddin Jamal Rawa ${ }^{2,5}$ (D) \\ and Hegazy Rezk 6,7 (D)
}

check for updates

Citation: Alhumade, H.; Fathy, A.; Al-Zahrani, A.; Rawa, M.J.; Rezk, H. Optimal Parameter Estimation Methodology of Solid Oxide Fuel Cell Using Modern Optimization. Mathematics 2021, 9, 1066. https:// doi.org/10.3390/math9091066

Academic Editor: Nicu Bizon

Received: 27 March 2021

Accepted: 4 May 2021

Published: 10 May 2021

Publisher's Note: MDPI stays neutral with regard to jurisdictional claims in published maps and institutional affiliations.

Copyright: (C) 2021 by the authors. Licensee MDPI, Basel, Switzerland. This article is an open access article distributed under the terms and conditions of the Creative Commons Attribution (CC BY) license (https:/ / creativecommons.org/licenses/by/ $4.0 /)$.
1 Department of Chemical and Materials Engineering, Faculty of Engineering, King Abdulaziz University, Jeddah 21589, Saudi Arabia; azahrani@kau.edu.sa

2 Center of Research Excellence in Renewable Energy and Power systems, King Abdulaziz University, Jeddah 21589, Saudi Arabia; mrawa@kau.edu.sa

3 Electrical Engineering Department, Faculty of Engineering, Jouf University, Sakaka 72388, Saudi Arabia; afali@ju.edu.sa

4 Electrical Power and Machine Department, Faculty of Engineering, Zagazig University, Zagazig 44519, Egypt

5 Department of Electrical and Computer Engineering, Faculty of Engineering, King Abdulaziz University, Jeddah 21589, Saudi Arabia

6 College of Engineering at Wadi Addawaser, Prince Sattam Bin Abdulaziz University, Al-Kharj 11911, Saudi Arabia; hr.hussien@psau.edu.sa

7 Electrical Engineering Department, Faculty of Engineering, Minia University, Minia 61517, Egypt

* Correspondence: halhumade@kau.edu.sa

\begin{abstract}
An optimal parameter estimation methodology of solid oxide fuel cell (SOFC) using modern optimization is proposed in this paper. An equilibrium optimizer (EO) has been used to identify the unidentified parameters of the SOFC equivalent circuit with the assistance of experimental results. This is presented via formulating the modeling process as an optimization problem considering the sum mean squared error (SMSE) between the observed and computed voltages as the target. Two modes of the SOFC-based model are investigated under variable operating conditions, namely, the steady-state and the dynamic-state based models. The proposed EO results are compared to those obtained via the Archimedes optimization algorithm (AOA), Heap-based optimizer (HBO), Seagull Optimization Algorithm (SOA), Student Psychology Based Optimization Algorithm (SPBO), Marine predator algorithm (MPA), Manta ray foraging optimization (MRFO), and comprehensive learning dynamic multi-swarm marine predators algorithm. The minimum fitness function at the steady-state model is obtained via the proposed $\mathrm{EO}$ with value of $1.5527 \times 10^{-6}$ at $1173 \mathrm{~K}$. In the dynamic based model, the minimum SMSE is 1.0406 . The obtained results confirmed the reliability and superiority of the proposed EO in constructing a reliable model of SOFC.
\end{abstract}

Keywords: solid oxide fuel cell; parameter identification; optimization

\section{Introduction}

There is a growing demand for energy to meet the requirements of continuous industrial development and modern civilization. In parallel, there is a growing concern about the depletion of traditional energy sources such as fossil fuel and drawbacks of continuous consumption of fossil fuel such as climate change [1]. Indeed, a recent study expected that future energy demands might exceed the limits of current energy systems [2]. Moreover, the increasing global energy demands and consumption of fossil fuel will escalate the emissions of greenhouse gases and other toxic air pollutants. Therefore, alternative sources of energy such as renewable energy have earned significant attention in the recent decades. In particular, fuel cell is among the power generation systems that can deliver environmentally friendly quality energy with great energy conversion efficiency. Furthermore, fuel cell has a great potential in power delivery for stationary and movable applications compared to other storage technologies [3-7]. Other remarkable features of fuel cell over other energy 
alternatives include lower fuel oxidation temperature and reduced emissions [8]. Solid oxide fuel cell (SOFC) and polymer composites-based electrolyte fuel cell represent the most attractive types of fuel cell for a wide range of applications. A growing effort is made to deliver a model that can predict the performance of fuel cell over steady state or dynamics operating environmental conditions [9-12]. In fact, appropriate model identification requires feeding accurate input parameters to the governing equations that encompass physical and chemical properties of the cell, where the modelling methodologies can be empirical, semi-empirical, or theoretical [13-16].

The parameter extraction of the fuel cell model plays an important role in the simulation, evaluation, control, and optimization of a fuel cell system. The voltage drops in SOFC are mainly reliant on the parameters associated with the chemical processes inside SOFC $[17,18]$. Several methods were used to identify the accurate parameters of SOFC. Among these methods, the metaheuristic optimization-based methodologies were superior in resolving the SOFC parameter estimation problem due to their reliability, robustness, and simplicity. Shi et al. [19] proposed a strategy, Converged Grass Fibrous Root, to determine the best parameters of the SOFC model. Both temperature and pressure variation are considered. During the optimization process, seven parameters are assigned to be decision variables: the standard potential, the current limitation density, the Tafel line slope, a constant depends on the operating state of SOFC, the area-specific resistance, the anode exchange current density, and the cathode exchange current density. El-Hay et al. [10] suggested a methodology based on an interior search algorithm to estimate the steady state and transient parameters of SOFC. A proportional-integral controller is integrated with the dynamic model to enhance its performance throughout transient disturbances. A similar study also carried by the same authors based on Satin Bowerbird Optimizer was conducted [9]. During the optimization process, the decision variables are represented by the unknown parameters of SOFC, whereas the cost function is represented by mean squared deviations between experimental data and estimated SOFC voltages. In the same direction, Yousri et al. [20] proposed a modified algorithm called comprehensive learning dynamic multi-swarm marine predators to determine both static and dynamic parameters of SOFC. During the optimization process, the mean squared error between the experimental data and estimated SOFC voltage is used as the objective function that is required to be minimum. Nassef et al. [21] used the radial movement optimization algorithm (RMOA) to determine the best parameters of the SOFC model. The model of SOFC was created using a neural network. During the optimization process, four parameters, including electrolyte thickness, cathode interlayer thickness, anode porosity, and anode support layer thickness, are used as decision variables; in contrast, the objective function is represented by the power density of SOFC. By using the RMOA, the power density was increased by $17.28 \%$ compared with the genetic algorithm. In the same direction, Fathy et al. [22] suggested a methodology based on the moth-flame optimization algorithm (MFOA). The power density of SOFC using the MFOA was improved. It was increased by $18.92 \%$ and $5.56 \%$ compared to the genetic algorithm and RMOA, respectively.

The contribution of the current research work can be summarized as follows:

- A novel approach based on Equilibrium Optimizer (EO) is suggested to determine the optimal parameters of the SOFC-based model.

- The suggested methodology is validated through both steady-state and dynamic-state models of SOFC with the changing of the operational conditions.

- A comprehensive comparison with previous works and other programs of the Archimedes optimization algorithm (AOA), Heap-based optimizer (HBO), Seagull Optimization Algorithm (SOA), Student Psychology Based Optimization Algorithm (SPBO), Marine predator algorithm (MPA), and Manta ray foraging optimization (MRFO).

- The superiority and reliability of the suggested EO-based strategy in solving the SOFC parameter determination problem is verified. 
The rest of the paper is organized as follows: The mathematical model of SOFC is illustrated in Section 2. Section 3 presents an overview about main aspects of the equilibrium optimizer. Then, the suggested optimization problem and solution methodology are explained in Section 4. Section 5 presents a detailed discussion of the obtained results and a comparative study with other methods. Finally, the main findings and the future work are outlined in Section 6.

\section{SOFC Mathematical Model}

In this section, the authors illustrate the static- and dynamic-based models of SOFC.

\subsection{Steady-State Model}

The output voltage of SOFC can be estimated using the following relation considering the activation loss, ohmic loss, and concentration loss [23]:

$$
V_{\text {cell }}=E_{n}-V_{a}-V_{o}-V_{c}
$$

where $E_{n}$ denotes the reversible voltage of the cell, and $V_{a}, V_{o}$, and $V_{c}$ denote the activation, $\mathrm{ohm}$, and concentration voltage drops, respectively.

The activation loss, concentration loss and ohmic loss can be estimated using the following relations:

$$
\begin{gathered}
V_{a}=a \cdot \ln \left(\frac{J}{2 J_{0}}\right) \\
V_{o}=\sum_{k} i \times R_{k} \\
V_{c}=-b \cdot \ln \left(1-\frac{J}{J_{\max }}\right)
\end{gathered}
$$

where $a$ and $b$ are constants; $J$ denotes the current density; $J_{0}$ denotes the exchange current density; $J_{\max }$ is the maximum current density; $R_{k}$ is the sum of ionic (electrolyte) and electronic resistances; and $i$ denotes the output SOFC current.

To increase the rating voltage of SOFC, the number of cells are connected in series. Therefore, the total stack output voltage can be estimated using the following relation.

$$
V_{s}=n_{c} \times V_{\text {cell }}=n_{c} \times\left(E_{n}-V_{a}-V_{o}-V_{c}\right)
$$

where vs. is the stack voltage and $n_{c}$ is the number of cells. The reversible voltage can be written as follows [24]:

$$
E_{n}=E_{0}+\frac{R T}{2 F} \ln \left(\frac{P_{\mathrm{H}_{2}} \sqrt{P_{\mathrm{O}_{2}}}}{P_{\mathrm{H}_{2} \mathrm{O}}}\right)
$$

where $E_{0}$ denotes the reference voltage at unit activity and atmospheric pressure; $T$ denotes operating temperature (K); $P_{\mathrm{H}_{2}}, P_{\mathrm{O}_{2}}$, and $P_{\mathrm{H}_{2} \mathrm{O}}$ denote the hydrogen, oxygen, and water partial pressures, respectively; $R$ is the universal gas constant with a value of $8.314 \mathrm{~kJ}$ $(\mathrm{kmol} \mathrm{K})^{-1}$; and $F$ is the Faraday constant.

\subsection{SOFC Dynamic Model}

The gas molar flow in SOFC is reliant on hydrogen and oxygen partial pressures as follows [24]:

$$
\begin{aligned}
& \frac{q_{H_{2}}}{P_{H_{2}}}=\frac{k_{a n}}{\sqrt{M_{H_{2}}}}=K_{H_{2}} \\
& \frac{q_{O_{2}}}{P_{\mathrm{O}_{2}}}=\frac{k_{a n}}{\sqrt{M_{\mathrm{O}_{2}}}}=K_{O_{2}}
\end{aligned}
$$


where $q_{\mathrm{H}_{2}}$ is the molar flow of hydrogen; $q_{\mathrm{O}_{2}}$ is the molar flow of oxygen; $K_{\mathrm{H}_{2}}$ is the hydrogen molar constant; $\mathrm{K}_{\mathrm{O}_{2}}$ is the oxygen molar constant; $k_{a n}$ is the anode valve constant; $M_{H_{2}}$ is the molar masses of hydrogen; and $M_{\mathrm{O}_{2}}$ is the molar masses of oxygen.

The partial pressure derivative can be estimated using the following relation:

$$
\frac{d P_{\mathrm{H}_{2}}}{d t}=\frac{R T}{V_{a n}}\left(q_{H_{2}}{ }^{\text {in }}-q_{H_{2}}{ }^{\text {out }}-q_{H_{2}}{ }^{r}\right)
$$

where $V_{a n}$ denotes the anode volume; $q_{H_{2}}{ }^{i n}$ is the hydrogen input flow rate; $q_{\mathrm{H}_{2}}{ }^{\text {out }}$ is the hydrogen output flow rate; and ${q_{H_{2}}}^{r}$ denotes the reacted hydrogen flow rate.

The reacted hydrogen flow rate can be estimated based on the following relation:

$$
q_{H_{2}}{ }^{r}=\frac{n_{c} i}{2 F}=2 K_{r} i
$$

where $K_{r}$ is constant.

Considering the above equations and the Laplace transform, hydrogen and oxygen partial pressures can be formulated as follows.

$$
\begin{gathered}
P_{\mathrm{H}_{2}}(s)=\frac{1 / K_{\mathrm{H}_{2}}}{1+\tau_{\mathrm{H}_{2}}}\left(q_{\mathrm{H}_{2}}{ }^{i n}-2 K_{r} i\right) \\
P_{\mathrm{H}_{2} \mathrm{O}}(s)=\frac{1 / K_{\mathrm{H}_{2} \mathrm{O}}}{1+\tau_{\mathrm{H}_{2} \mathrm{O}}}\left(2 K_{r} i\right) \\
P_{\mathrm{O}_{2}}(s)=\frac{1 / K_{\mathrm{O}_{2}}}{1+\tau_{\mathrm{O}_{2}}}\left(q_{\mathrm{O}_{2}}{ }^{i n}-K_{r} i\right)
\end{gathered}
$$

where $\tau_{\mathrm{H}_{2}}, \tau_{\mathrm{H}_{2} \mathrm{O}}$, and $\tau_{\mathrm{O}_{2}}$ denote the flow time constants of hydrogen, water, and oxygen, respectively.

Ultimately, the dynamic model of SOFC voltage is given by the following relation.

$$
V_{s}=n_{c}\left(E_{0}+\frac{R T}{2 F}\left(\ln \frac{P_{\mathrm{H}_{2}} \sqrt{P_{\mathrm{O}_{2}}}}{P_{\mathrm{H}_{2}}}\right)\right)-\left(a \cdot \ln \left(\frac{J}{2 J_{0}}\right)+r \times i-b \cdot \ln \left(1-\frac{J}{J_{\max }}\right)\right)
$$

\section{Overview of Equilibrium Optimizer}

Equilibrium optimizer (EO) is a recent algorithm that was proposed by Faramarzi et al. in 2020 [25]. The core idea of the EO is extracted from the control volume mass balance models. During the optimization process of the EO, the particles and positions are assigned to the solutions and concentrations, respectively. The details explanations about the inspiration, mathematical model, and algorithm of the EO can be found in [25]. The mass balance formula is expressed as follows.

$$
V \frac{d C}{d t}=Q C_{e q}-Q C-G
$$

where $C$ denotes the concentration of the control volume; $V \frac{d C}{d t}$ denotes the changing rate of the mass; $Q$ denotes the flow rate; $C_{e q}$ denotes the concentration at the balance state; and $G$ denotes the mass generation rate.

By integration over time and rearranged with the above formula, the following relation can be used to express the concentration of the control volume.

$$
C=C_{e q}+\left(C_{0}-C_{e q}\right) F+\frac{G}{\lambda V}(1-f)
$$

where $\lambda$ denotes the turnover rate $(\lambda=Q / V)$ and $f=e^{-\lambda\left(t-t_{0}\right)}$, and $t_{0}$ and $C_{0}$ denote the initial time and concentration, respectively. 
The time $t$ is decreasing with increasing the number of iterations as follows:

$$
\begin{gathered}
t=(1-I / z))^{\left(a_{2} \frac{I}{z}\right)} \\
\overrightarrow{t_{0}}=\frac{1}{\vec{\lambda}} \ln \left(-a_{1} \operatorname{sign}(\vec{r}-0.5)\left[1-e^{\overrightarrow{\lambda t}}\right]\right)+t \\
\vec{F}=a_{1} \operatorname{sign}(\vec{r}-0.5)\left[1-e^{\overrightarrow{\lambda t}}\right]
\end{gathered}
$$

where $I$ and $z$ are the current iteration and maximum number of iterations, respectively. $a_{1}$ and $a_{2}$ are constants. $\vec{r}$ is a random vector in range $[0,1]$.

Considering Equation (16), there are three sections describing the updating process for particles. The first section represents the equilibrium concentration. It represents the optimum solutions arbitrarily chosen from a pool. The second section is related to the concentration variations between a particle and the equilibrium state. The last section is related to the generation rate. It is mainly performing the role of an exploiter. The equilibrium state is the final convergence state of the EO optimization process. The equilibrium pool can be represented as follows.

$$
\vec{C}_{\text {eq.pool }}=\left\{\vec{C}_{e q(1)}, \vec{C}_{e q(2)}, \vec{C}_{e q(3)}, \vec{C}_{e q(4)}, \vec{C}_{e q(\text { ave })}\right\}
$$

During the first iteration, the particle modifies the concentration using $\vec{C}_{e q(1)}$ whereas it is uses $\vec{C}_{e q(a v e)}$ with other iterations. The generation rate is defined as follows.

$$
\vec{G}=\overrightarrow{G_{0}} e^{-\vec{k}\left(t-t_{0}\right)}
$$

where $G_{0}$ is the initial value, and $k$ denotes a decay constant $(k=\lambda)$.

$$
\begin{gathered}
\vec{G}=\vec{G}_{0} e^{-\vec{\lambda}\left(t-t_{0}\right)}=\vec{G}_{0} \vec{F} \\
\vec{G}_{0}=\overrightarrow{G C} P\left(\vec{C}_{e q}-\vec{\lambda} \vec{C}\right) \\
\overrightarrow{G C P}= \begin{cases}0.5 r_{1} & r_{2} \geq G P \\
0 & r_{2}<G P\end{cases}
\end{gathered}
$$

where $r_{1}$ and $r_{2}$ are random variables in range $[0,1]$, and GCP is a parameter that controls the generation rate.

The addition of memory saving helps each particle to save its coordinates in the search space. Moreover, it informs its fitness function value. The fitness function related to a particular particle in the ongoing iteration is compared with the previous one; then, the updating process is placed if it reaches better fit. This action enhances the exploitation phase. The optimization process of EO is illustrated in Figure 1. 


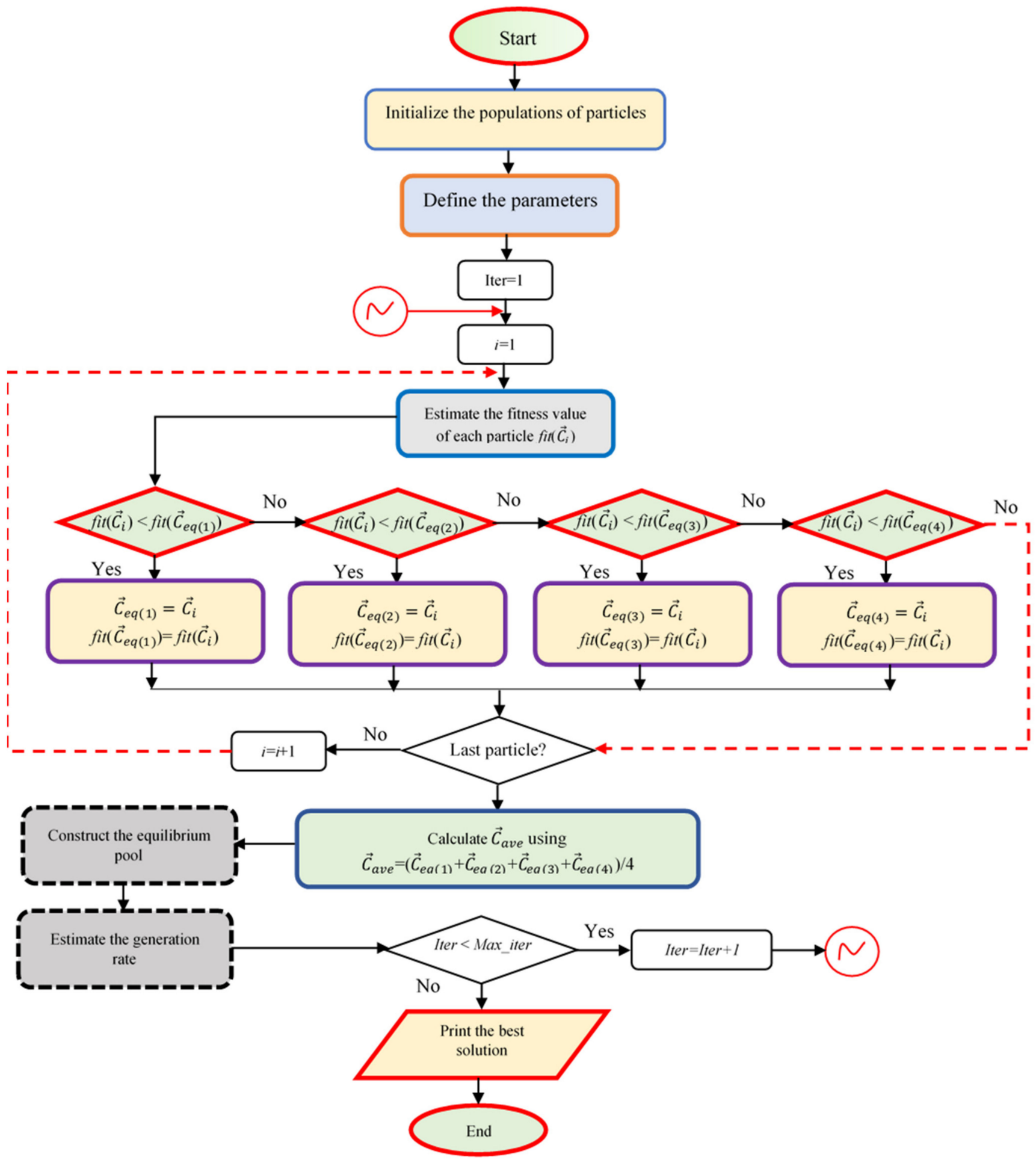

Figure 1. Optimization process of EO.

\section{The Proposed Methodology}

In this section, the proposed methodology is explained via formulating the problem of SOFC parameter estimation as an optimization problem, and an objective function and corresponding constraints are also introduced. Moreover, the proposed solution methodology is also presented. 


\subsection{The Proposed Objective Function}

In this section, the formulation of the identification process of SOFC circuit's parameters as an optimization problem is explained via specifying the fitness function, the corresponding constraints, and the proposed methodology of the solution incorporated by the EO. The main target of the work is to construct a reliable equivalent circuit of SOFC by identifying six parameters, $E_{0}, a, \mathrm{~J}_{0}, r, b$, and $J_{\max }$; this is achieved with the aid of experimental data of the current and voltage of FC. The fitness function represented in this work is the sum mean squared error between the measured and calculated terminal voltages of SOFC, and this can be described as follows:

$$
\text { Minimize } \quad S M S E=\sum_{k=1}^{N} \frac{1}{N}\left(V_{\text {meas }, k}-V_{\text {cal }, k}\right)^{2}
$$

where $V_{\text {meas }, k}$ and $V_{\text {cal }, k}$ are the $k^{\text {th }}$ observed and computed voltages, respectively, and $N$ is the number of measured datasets. The constraints related to the variables to be designed can be described as follows:

$$
\begin{aligned}
& E_{0}{ }^{\min } \leq E_{0} \leq E_{0} \max \\
& a^{\min } \leq a \leq a_{\max } \\
& J_{o}{ }^{\min } \leq J_{0} \leq J_{o} \max \\
& r^{\min } \leq r \leq r^{\max } \\
& b^{\min } \leq b \leq b^{\max } \\
& J_{\max }{ }^{\min } \leq x_{6} \leq J_{\max }{ }_{\max }
\end{aligned}
$$

where min denotes the minimum limit and max denotes the maximum limit. In this work the authors only considered the disturbance on the SOFC output voltage. However, in future work, they will consider the disturbance not only on the SOFC output but also on the SOFC input such as those given in [26-29].

\subsection{The Proposed EO Based Methodology}

The equilibrium optimizer is selected due to many advantages: It is simple in implementation; it achieves balance between the exploration and exploitation phases; and there is diversity between the population individuals. These features enable the algorithm to be applicable for many optimization problems. Six parameters are required to be identified such that the SMSE is minimized. The proposed methodology incorporating the EO begins by defining the specifications of SOFC and the recorded measured data of the terminal voltage. Then, an initial population with a dimension of $n_{p o p} \times \mathrm{dim}, n_{\text {pop }}$ is the population size, and dim is the problem dimension, which is constructed with the aid of the minimum and maximum limits defined by the user. The initial corresponding fitness function (SMSE) is calculated, and the iterative process is implemented by calculating the fitness function of each particle. The obtained fitness function is checked with those of the equilibrium pool to decide the updating action of each particle. After that, the condition of the last particle is investigated, and the average of the equilibrium pool is calculated, which helps in estimating the generation rate. The process is continued until the constraint of maximum iteration is achieved. At this moment, the optimal results are obtained and can be printed. The proposed methodology incorporating EO is shown in Figure 2. 


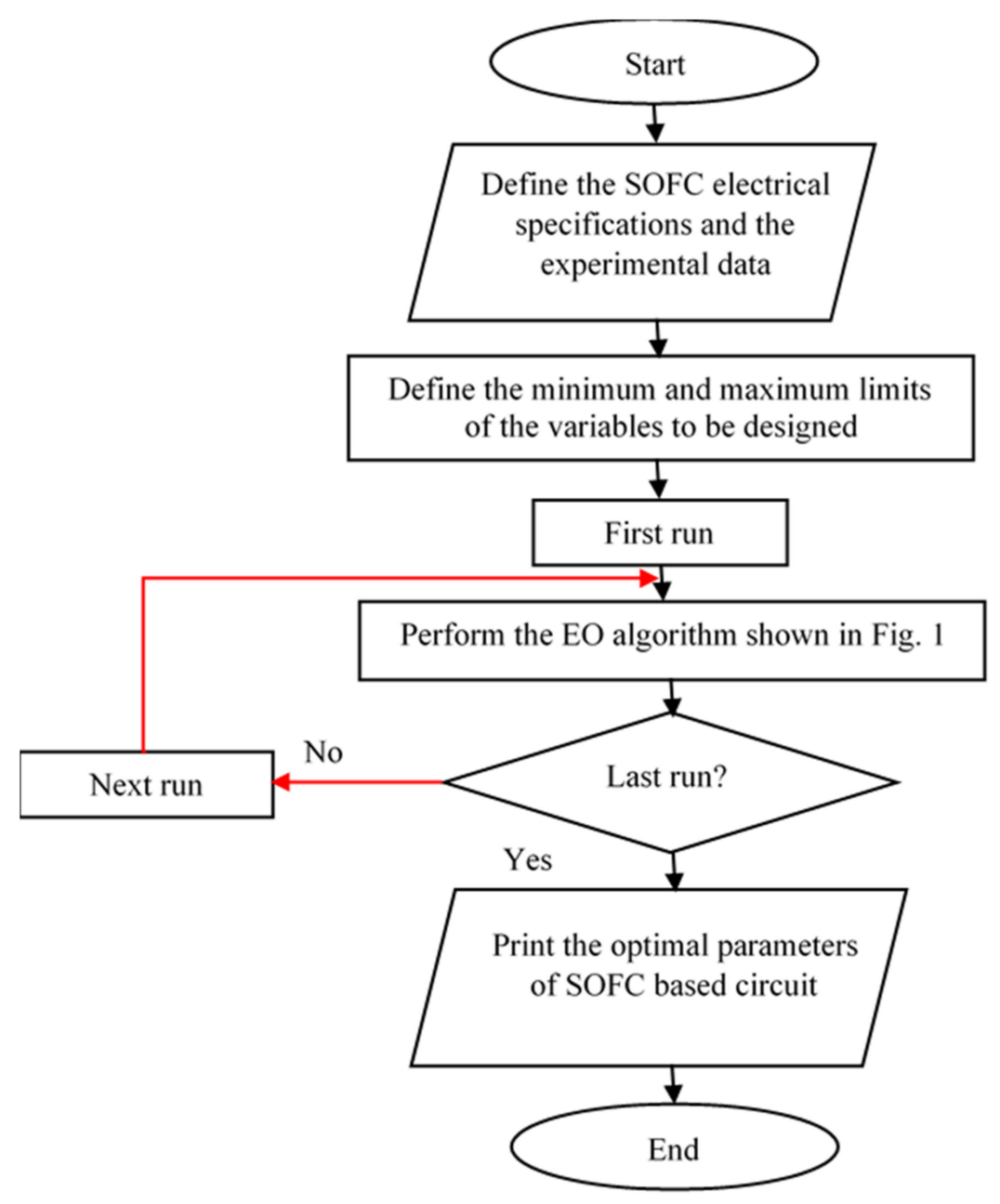

Figure 2. The proposed steps incorporating EO.

\section{Numerical Analysis}

The analysis is performed on two modes of the SOFC operation which are steady-state and dynamic-state. Both of them are investigated under variable-operating conditions. The commercial SOFC, which is manufactured by Siemens [30], is employed in steady-state analysis. In such a case, four measured datasets are recorded at temperatures of 1073, 1173, 1213 , and $1273 \mathrm{~K}$, where the proposed EO size of population is assigned as 50, and the number of iterations is selected as 100. The population-based approach presented in this work has some difficulty, such as getting premature and local optima, and the authors take into consideration this problem by performing the approach with 50 independent runs, and the best one is selected as global optima. This action minimizes the problem of falling in local optima. Other metaheuristic approaches are implemented and compared to the proposed EO; these algorithms are the Archimedes optimization algorithm (AOA), Heap-based optimizer (HBO), Seagull Optimization Algorithm (SOA), Student Psychology Based Optimization Algorithm (SPBO), Marine predator algorithm (MPA), Manta ray foraging optimization (MRFO), and comprehensive learning dynamic multi-swarm marine predators algorithm CLDMMPA [20]. Table 1 shows the obtained optimal parameters of SOFC operated at $1073 \mathrm{~K}$ via the proposed $\mathrm{EO}$ and the others. The proposed approach succeeded in achieving a fitness function of $2.6906 \times 10^{-6}$ which is the same obtained via CLDMMPA. However, the CLDMMPA is complex in construction; moreover, the proposed EO consumes only $272.198102 \mathrm{~s}$, which is the best compared to the others. The measured and calculated polarization curves obtained via the proposed EO are shown in Figure 3. Both curves are closely converged. Moreover, Figure 4 shows the estimated polarization curves obtained via the other approaches and the measured ones. Furthermore, 
the performance of each optimizer during the iterative process is shown in Figure 5. It is clear that the EO performance is the best compared to the others.

Table 1. The optimal parameters of SOFC steady-state based model operated at $1073 \mathrm{~K}$.

\begin{tabular}{|c|c|c|c|c|c|c|}
\hline & $\begin{array}{c}\text { CLDMMPA } \\
\text { [20] }\end{array}$ & MPA & HBO & SOA & MRFO & $\begin{array}{c}\text { The Proposed } \\
\text { EO }\end{array}$ \\
\hline$E_{0}(\mathrm{~V})$ & 0.90754 & 0.9127 & 0.91214 & 0.91101 & 0.91827 & 0.91056 \\
\hline$a(\mathrm{~V})$ & 0.010741 & 0.011058 & 0.010929 & 0.020502 & 0.0116 & 0.010724 \\
\hline$J_{o}\left(\mathrm{~A} / \mathrm{cm}^{2}\right)$ & 0.098627 & 0.059994 & 0.063321 & 0.048127 & 0.035918 & 0.074522 \\
\hline$r\left(\mathrm{k} \Omega \cdot \mathrm{cm}^{2}\right)$ & 1.0 & 1.0 & 1.0 & 1.0 & 0.99919 & 1.0 \\
\hline$b(\mathrm{~V})$ & 0.044104 & 0.042784 & 0.043502 & 0.0 & 0.036886 & 0.044165 \\
\hline$J_{\max }\left(\mathrm{A} / \mathrm{cm}^{2}\right)$ & 1.0 & 1.0 & 1.0 & 0.64297 & 0.9183 & 1.0 \\
\hline Elapsed time (sec.) & NA & 468.526 & 403.607 & 278.254 & 560.753 & 272.198102 \\
\hline SMSE & $2.6906 \times 10^{-6}$ & $2.692 \times 10^{-6}$ & $2.7003 \times 10^{-6}$ & $4.123 \times 10^{-6}$ & $2.7213 \times 10^{-6}$ & $2.6906 \times 10^{-6}$ \\
\hline
\end{tabular}

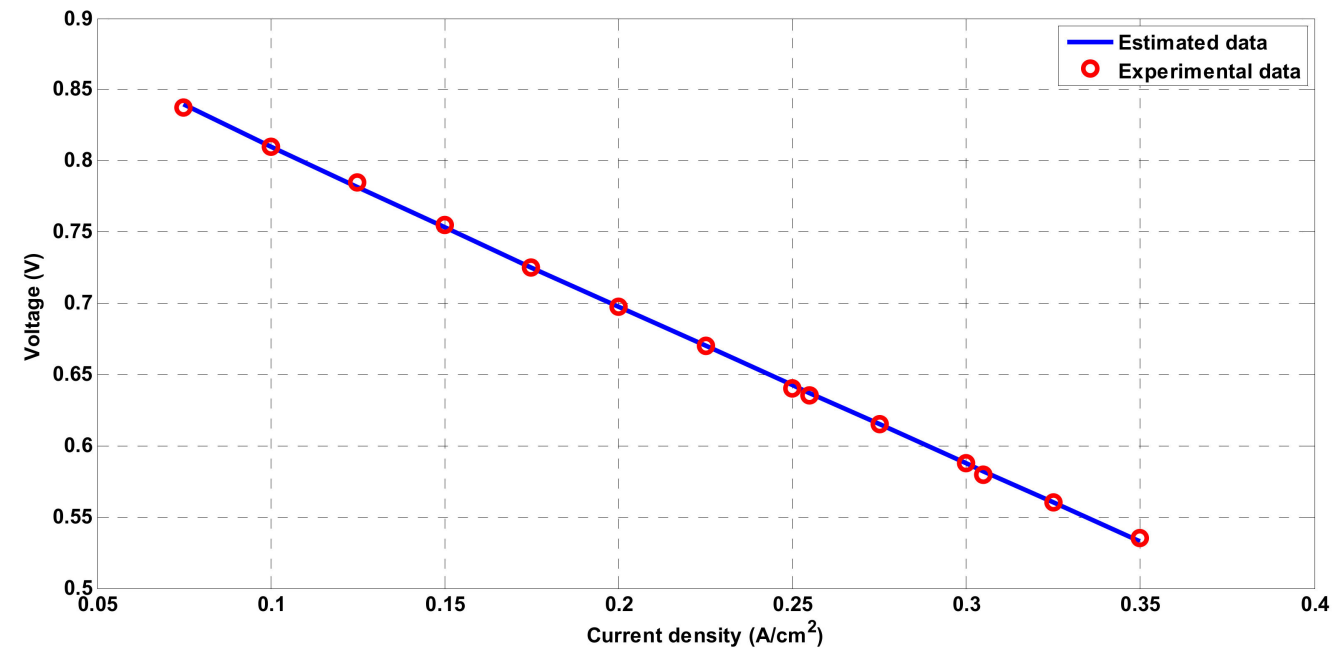

(a)

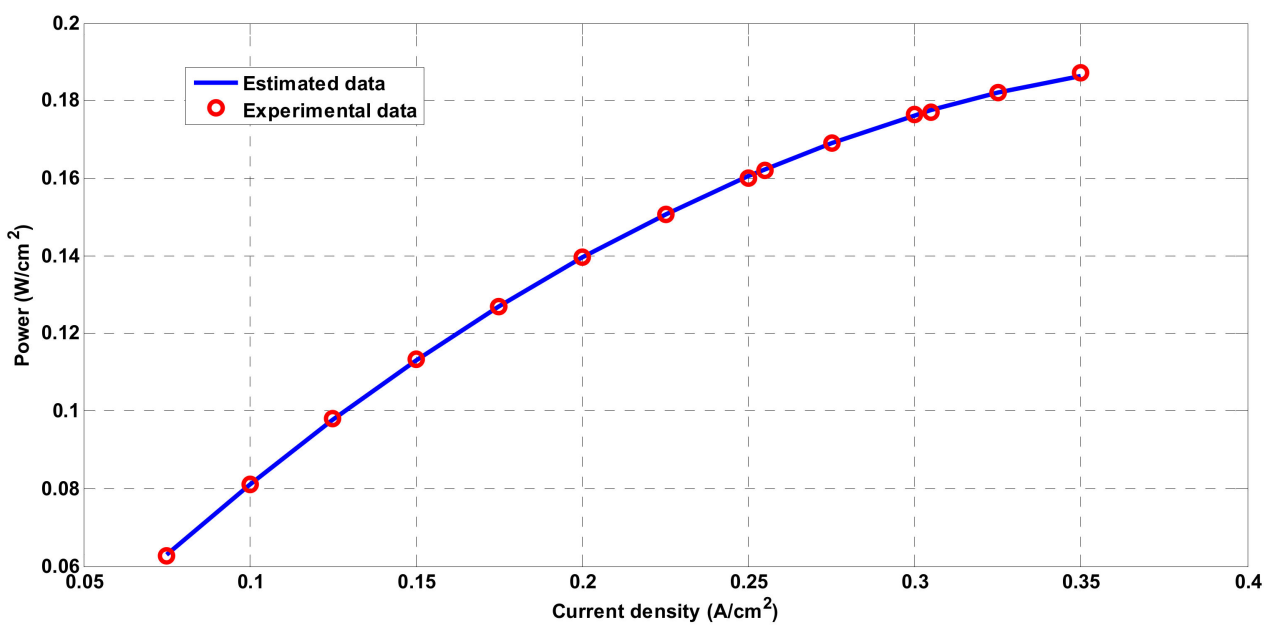

(b)

Figure 3. The measured and calculated polarization curves of SOFC operated at $1073 \mathrm{~K}$ obtained via EO at (a) current density-voltage, (b) current density-power. 

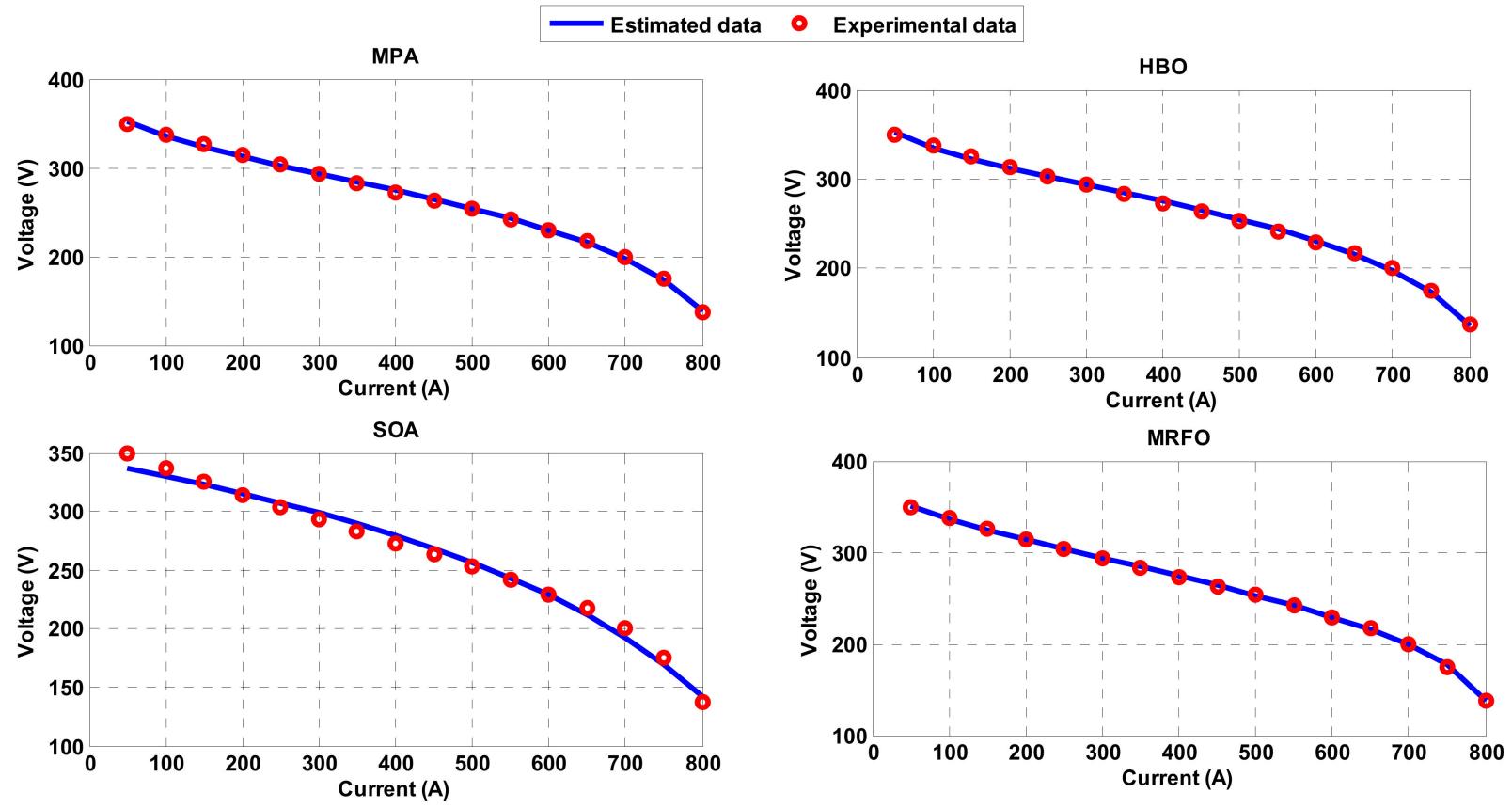

(a)
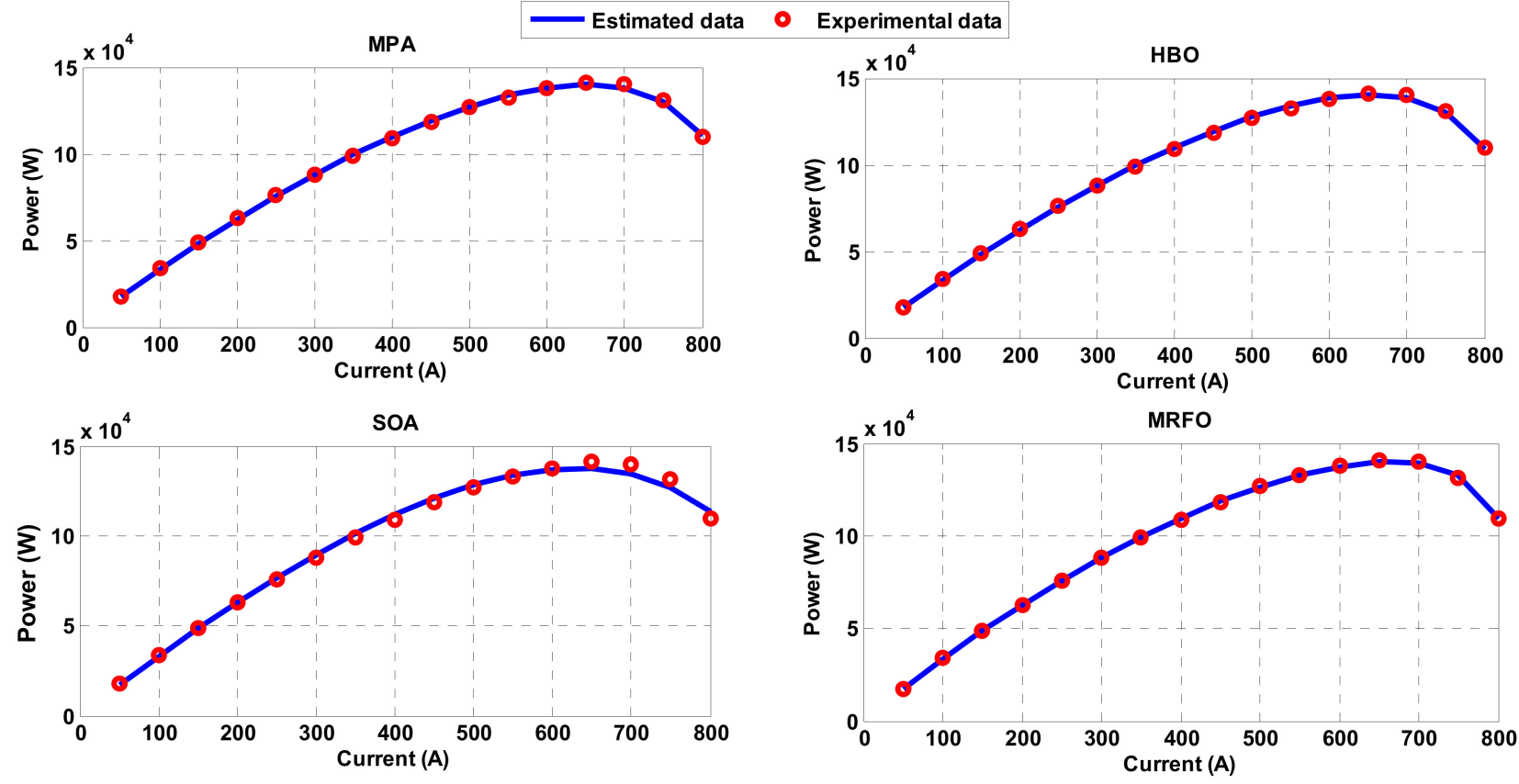

(b)

Figure 4. (a) Current-voltage curve, (b) Current-power curve of SOFC operated at $1073 \mathrm{~K}$ obtained via other approaches. 


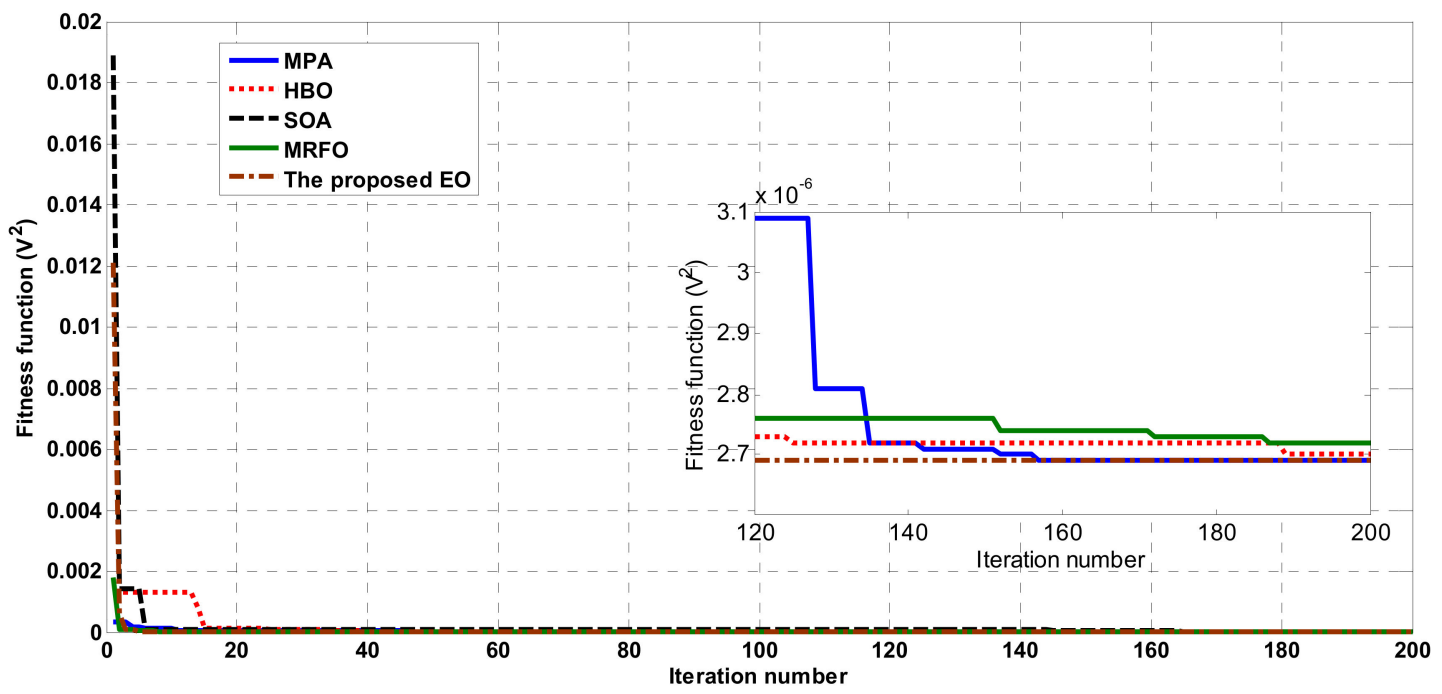

Figure 5. The variation of fitness function during iterative process for all employed optimizers applied for steady-state SOFC model.

The optimal parameters of the SOFC steady-state based model at 1173, 1213, and $1273 \mathrm{~K}$ obtained via the proposed EO and the others are tabulated in Tables $2-4$. Regarding the obtained results at $1173 \mathrm{~K}$, the best fitness function is $1.5527 \times 10^{-6}$ obtained via the proposed EO while CLDMMPA comes in the second rank with a SMSE of $1.5529 \times 10^{-6}$. On the other hand, the worst approach is SOA with a fitness function of $3.1657 \times 10^{-6}$. Moreover, during the operation at $1213 \mathrm{~K}$, the EO outperformed the others in terms of elapsed time and fitness function. The reader can see that during operation at $1273 \mathrm{~K}$, the proposed EO achieved a SMSE of $2.2995 \times 10^{-6}$, which is the best compared to the others.

Table 2. The optimal parameters of SOFC steady-state based model operated at $1173 \mathrm{~K}$.

\begin{tabular}{|c|c|c|c|c|c|c|}
\hline & $\begin{array}{c}\text { CLDMMPA } \\
\text { [20] }\end{array}$ & MPA & HBO & SOA & MRFO & $\begin{array}{c}\text { The Proposed } \\
\text { EO }\end{array}$ \\
\hline$E_{0}(\mathrm{~V})$ & 0.89103 & 0.89129 & 0.89083 & 0.87956 & 0.89087 & 0.89108 \\
\hline$a(\mathrm{~V})$ & $3.671 \times 10^{-13}$ & $6.1748 \times 10^{-13}$ & $3.23334 \times 10^{-13}$ & 0.0077567 & $9.8137 \times 10^{-6}$ & $3.14568 \times 10^{-8}$ \\
\hline$J_{o}\left(\mathrm{~A} / \mathrm{cm}^{2}\right)$ & 0.095127 & 0.018358 & 0.041194 & 0.087363 & 0.068684 & 0.09998 \\
\hline$r\left(\mathrm{k} \Omega \cdot \mathrm{cm}^{2}\right)$ & 0.40473 & 0.41593 & 0.39952 & 0.21139 & 0.4027 & 0.40610 \\
\hline$b(\mathrm{~V})$ & 0.18841 & 0.17741 & 0.19212 & 0.28497 & 0.18885 & 0.18741 \\
\hline$J_{\max }\left(\mathrm{A} / \mathrm{cm}^{2}\right)$ & 1.0 & 0.98862 & 1.0 & 0.9465 & 0.9968 & 0.99999 \\
\hline $\begin{array}{l}\text { Elapsed time } \\
\text { (sec.) }\end{array}$ & NA & 495.653992 & 396.181972 & 303.170716 & 612.841366 & 303.185040 \\
\hline SMSE & $1.5529 \times 10^{-6}$ & $1.5594 \times 10^{-6}$ & $1.5557 \times 10^{-6}$ & $3.1657 \times 10^{-6}$ & $1.5563 \times 10^{-6}$ & $1.5527 \times 10^{-6}$ \\
\hline
\end{tabular}

Table 3. The optimal parameters of SOFC steady-state based model operated at $1213 \mathrm{~K}$.

\begin{tabular}{ccccccc}
\hline & $\begin{array}{c}\text { CLDMMPA } \\
\text { [20] }\end{array}$ & MPA & HBO & SOA & MRFO & $\begin{array}{c}\text { The Proposed } \\
\text { EO }\end{array}$ \\
& 0.86169 & 0.86189 & 0.86134 & 0.85622 & 0.86176 & 0.86164 \\
$E_{0}(\mathrm{~V})$ & $5.0588 \times 10^{-13}$ & $4.2805 \times 10^{-28}$ & $3.4456 \times 10^{-30}$ & $3.1223 \times 10^{-29}$ & $3.3451 \times 10^{-5}$ & $7.12575 \times 10^{-8}$ \\
$a(\mathrm{~V})$ & 0.08871 & 0.054568 & 0.011975 & 0.047885 & 0.063468 & 0.07768 \\
$J_{o}\left(\mathrm{~A} / \mathrm{cm}^{2}\right)$ & 0.15982 & 0.16633 & 0.14858 & 0.000124 & 0.16629 & 0.15873 \\
$r\left(\mathrm{k} \Omega \cdot \mathrm{cm}^{2}\right)$ & 0.28529 & 0.28032 & 0.29351 & 0.4012 & 0.27918 & 0.28603 \\
$b(\mathrm{~V})$ & 1.0 & 0.99946 & 1.0 & 1.0 & 0.99732 & 0.99999 \\
$J_{\max }\left(\mathrm{A} / \mathrm{cm}^{2}\right)$ & $\mathrm{NA}$ & 464.968854 & 367.890819 & 236.154633 & 571.548052 & 273.530 \\
Elapsed time & $2.6811 \times 10^{-6}$ & $2.6846 \times 10^{-6}$ & $2.6887 \times 10^{-6}$ & $4.3804 \times 10^{-6}$ & $2.6896 \times 10^{-6}$ & $2.6809 \times 10^{-6}$ \\
(sec.) & & & & &
\end{tabular}


Table 4. The optimal parameters of SOFC steady-state based model operated at $1273 \mathrm{~K}$.

\begin{tabular}{|c|c|c|c|c|c|c|}
\hline & $\begin{array}{c}\text { CLDMMPA } \\
\text { [20] }\end{array}$ & MPA & НВО & SOA & MRFO & $\begin{array}{c}\text { The Proposed } \\
\text { EO }\end{array}$ \\
\hline$E_{0}(\mathrm{~V})$ & 0.8478 & 0.84782 & 0.84802 & 0.84014 & 0.84802 & 0.8478 \\
\hline$a(\mathrm{~V})$ & $2.887 \times 10^{-14}$ & $3.128 \times 10^{-21}$ & $5.1251 \times 10^{-6}$ & $2.238 \times 10^{-20}$ & $3.2243 \times 10^{-5}$ & $6.7797 \times 10^{-12}$ \\
\hline$J_{o}\left(\mathrm{~A} / \mathrm{cm}^{2}\right)$ & 0.061816 & 0.014523 & 0.086283 & 0.017285 & 0.024437 & 0.0160 \\
\hline$r\left(\mathrm{k} \Omega \cdot \mathrm{cm}^{2}\right)$ & 0.21564 & 0.21634 & 0.22323 & 0.1563 & 0.22021 & 0.2169 \\
\hline$b(\mathrm{~V})$ & 0.20575 & 0.20524 & 0.20009 & 0.36046 & 0.20226 & 0.2047 \\
\hline$J_{\max }\left(\mathrm{A} / \mathrm{cm}^{2}\right)$ & 1.0 & 1.0 & 0.99984 & 1.00 & 0.99888 & 1.0 \\
\hline $\begin{array}{l}\text { Elapsed time } \\
\text { (sec.) }\end{array}$ & NA & 465.757529 & 352.634515 & 199.242260 & 555.636660 & 317.980527 \\
\hline SMSE & $2.2997 \times 10^{-6}$ & $2.2996 \times 10^{-6}$ & $2.3031 \times 10^{-6}$ & $5.4888 \times 10^{-6}$ & $2.3058 \times 10^{-6}$ & $2.2995 \times 10^{-6}$ \\
\hline
\end{tabular}

The polarization curves of the measured data and calculated data obtained via the proposed EO for the steady-state SOFC based model at 1173, 1213, and $1273 \mathrm{~K}$ are shown in Figure 6. The curves confirm the matching between the experimental and calculated data.

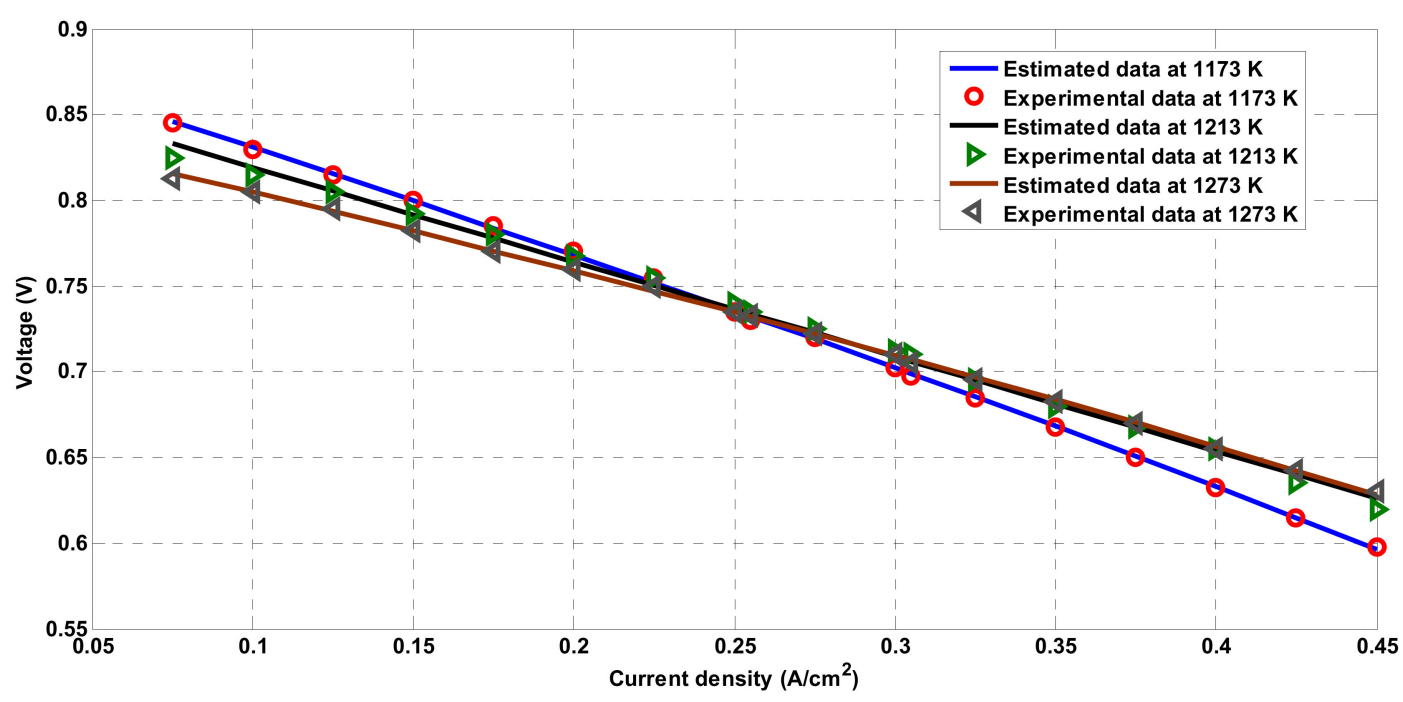

(a)

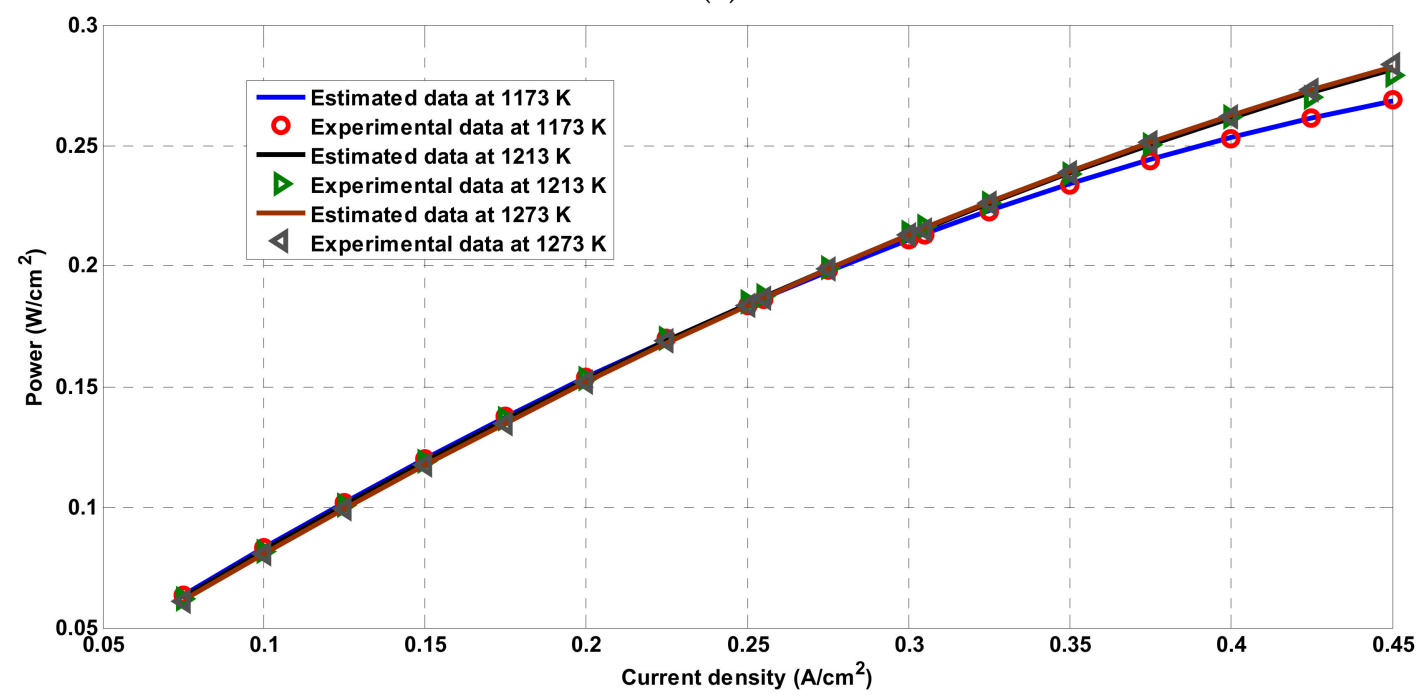

(b)

Figure 6. The measured and calculated (a) current density-voltage, (b) current density-power of SOFC operated at $1173 \mathrm{~K}$, $1213 \mathrm{~K}$, and $1273 \mathrm{~K}$ obtained via the proposed EO. 
It is important to investigate the performance of each optimizer via calculating the statistical parameters, which include the best, worst, mean, median, variance, and standard deviation after 50 independent runs. These data are calculated and tabulated in Table 5. The proposed EO gives acceptable statistical parameters compared to the others.

Table 5. Statistical parameters (best, worst, mean, median, variance, and standard deviation) of all optimizers used for steady-state SOFC model.

\begin{tabular}{|c|c|c|c|c|c|c|}
\hline \multicolumn{7}{|c|}{ At $T=1073 \mathrm{~K}$} \\
\hline & Cldmmpa [20] & MPA & НВО & SOA & MRFO & $\begin{array}{c}\text { The Proposed } \\
\text { EO }\end{array}$ \\
\hline Best & $2.6906 \times 10^{-6}$ & $2.69203 \times 10^{-6}$ & $2.70035 \times 10^{-6}$ & $4.12297 \times 10^{-6}$ & $2.7213 \times 10^{-6}$ & $2.6906 \times 10^{-6}$ \\
\hline Worst & $2.696 \times 10^{-6}$ & $1.23064 \times 10^{-5}$ & $4.49932 \times 10^{-6}$ & 0.00034 & $4.8504 \times 10^{-6}$ & $6.8151 \times 10^{-6}$ \\
\hline Mean & $2.6926 \times 10^{-6}$ & $4.75170 \times 10^{-6}$ & $3.11043 \times 10^{-6}$ & $9.38355 \times 10^{-5}$ & $3.1121 \times 10^{-6}$ & $3.3645 \times 10^{-6}$ \\
\hline Median & $2.6917 \times 10^{-6}$ & $3.61749 \times 10^{-6}$ & $2.96160 \times 10^{-6}$ & $9.33996 \times 10^{-5}$ & $2.9395 \times 10^{-6}$ & $2.6906 \times 10^{-6}$ \\
\hline Variance & $4.1347 \times 10^{-18}$ & $6.38059 \times 10^{-12}$ & $1.75759 \times 10^{-13}$ & $9.20085 \times 10^{-9}$ & $2.2231 \times 10^{-13}$ & $8.38802 \times 10^{-13}$ \\
\hline Std. deviation & $2.0334 \times 10^{-9}$ & $2.52598 \times 10^{-6}$ & $4.19236 \times 10^{-7}$ & $9.59210 \times 10^{-5}$ & $4.7150 \times 10^{-7}$ & $9.15673 \times 10^{-7}$ \\
\hline \multicolumn{7}{|c|}{ At $\mathrm{T}=1173 \mathrm{~K}$} \\
\hline & CLDMMPA [20] & MPA & $\mathrm{HBO}$ & SOA & MRFO & The proposed EO \\
\hline Best & $1.5529 \times 10^{-6}$ & $1.5594 \times 10^{-6}$ & $1.5556 \times 10^{-6}$ & $3.1656 \times 10^{-6}$ & $1.5563 \times 10^{-6}$ & $1.55279 \times 10^{-6}$ \\
\hline Worst & $1.5752 \times 10^{-6}$ & $5.9028 \times 10^{-6}$ & $2.1420 \times 10^{-6}$ & 0.01102 & $2.6603 \times 10^{-6}$ & $6.00407 \times 10^{-6}$ \\
\hline Mean & $1.5593 \times 10^{-6}$ & $3.0125 \times 10^{-6}$ & $1.6979 \times 10^{-6}$ & 0.00026 & $1.7105 \times 10^{-6}$ & $2.31364 \times 10^{-6}$ \\
\hline Median & $1.5572 \times 10^{-6}$ & $2.4861 \times 10^{-6}$ & $1.6532 \times 10^{-6}$ & $1.26093 \times 10^{-5}$ & $1.6493 \times 10^{-6}$ & $1.58630 \times 10^{-6}$ \\
\hline Variance & $3.8987 \times 10^{-17}$ & $1.9116 \times 10^{-12}$ & $1.8382 \times 10^{-14}$ & $2.42265 \times 10^{-6}$ & $3.7587 \times 10^{-14}$ & $2.66121 \times 10^{-12}$ \\
\hline Std. deviation & $6.244 \times 10^{-9}$ & $1.3826 \times 10^{-6}$ & $1.3558 \times 10^{-7}$ & 0.00155 & $1.9387 \times 10^{-7}$ & $1.63132 \times 10^{-6}$ \\
\hline \multicolumn{7}{|c|}{ At $\mathrm{T}=1213 \mathrm{~K}$} \\
\hline & CLDMMPA [20] & MPA & $\mathrm{HBO}$ & SOA & MRFO & The proposed EO \\
\hline Best & $2.6811 \times 10^{-6}$ & $2.6846 \times 10^{-6}$ & $2.6887 \times 10^{-6}$ & $4.3804 \times 10^{-6}$ & $2.68961 \times 10^{-6}$ & $2.68099 \times 10^{-6}$ \\
\hline Worst & $2.7269 \times 10^{-6}$ & $1.2325 \times 10^{-5}$ & $3.4295 \times 10^{-6}$ & 0.00032 & $3.22001 \times 10^{-6}$ & $1.30287 \times 10^{-5}$ \\
\hline Mean & $2.6921 \times 10^{-6}$ & $4.6204 \times 10^{-6}$ & $2.8357 \times 10^{-6}$ & $2.37574 \times 10^{-5}$ & $2.85206 \times 10^{-6}$ & $4.02438 \times 10^{-6}$ \\
\hline Median & $2.6867 \times 10^{-6}$ & $3.3119 \times 10^{-6}$ & $2.7703 \times 10^{-6}$ & $1.31251 \times 10^{-5}$ & $2.81486 \times 10^{-6}$ & $2.78147 \times 10^{-6}$ \\
\hline Variance & $1.9891 \times 10^{-16}$ & $9.4614 \times 10^{-12}$ & $2.7256 \times 10^{-14}$ & $3.77968 \times 10^{-9}$ & $1.72574 \times 10^{-14}$ & $1.12951 \times 10^{-11}$ \\
\hline Std. deviation & $1.4103 \times 10^{-8}$ & $3.0759 \times 10^{-6}$ & $1.6509 \times 10^{-7}$ & $6.14791 \times 10^{-5}$ & $1.3136 \times 10^{-7}$ & $3.36081 \times 10^{-6}$ \\
\hline \multicolumn{7}{|c|}{ At $\mathrm{T}=1273 \mathrm{~K}$} \\
\hline & CLDMMPA [20] & MPA & $\mathrm{HBO}$ & SOA & MRFO & The proposed EO \\
\hline Best & $2.2997 \times 10^{-6}$ & $2.2995 \times 10^{-6}$ & $2.30310 \times 10^{-6}$ & $5.4888 \times 10^{-6}$ & $2.30579 \times 10^{-6}$ & $2.2995 \times 10^{-6}$ \\
\hline Worst & $2.3392 \times 10^{-6}$ & $7.4728 \times 10^{-6}$ & $3.0608 \times 10^{-6}$ & 0.000247 & $2.84248 \times 10^{-6}$ & $7.6115 \times 10^{-6}$ \\
\hline Mean & $2.3156 \times 10^{-6}$ & $3.6859 \times 10^{-6}$ & $2.4184 \times 10^{-6}$ & $1.758508 \times 10^{-5}$ & $2.40213 \times 10^{-6}$ & $3.4890 \times 10^{-6}$ \\
\hline Median & $2.3141 \times 10^{-6}$ & $3.1707 \times 10^{-6}$ & $2.3647 \times 10^{-6}$ & $7.71186 \times 10^{-6}$ & $2.37664 \times 10^{-6}$ & $2.3085 \times 10^{-6}$ \\
\hline Variance & $1.3448 \times 10^{-16}$ & $2.1494 \times 10^{-12}$ & $1.9816 \times 10^{-14}$ & $2.25858 \times 10^{-9}$ & $8.64055 \times 10^{-15}$ & $4.8928 \times 10^{-12}$ \\
\hline Std. deviation & $1.1597 \times 10^{-8}$ & $1.466 \times 10^{-6}$ & $1.4077 \times 10^{-7}$ & $4.7524 \times 10^{-5}$ & $9.29545 \times 10^{-8}$ & $2.2119 \times 10^{-6}$ \\
\hline
\end{tabular}

The obtained results confirmed the superiority and reliability of the proposed methodology incorporating EO in identifying the optimal parameters of the SOFC steady-state based model.

It is important to confirm the availability of the presented approach in a dynamic/ transient-based model of SOFC. Therefore, a $100 \mathrm{~kW}$ stack with specifications given in Table 6 is modeled in a dynamic-state model subjected to variable load disturbances. At the beginning, the proposed EO is applied to identify the optimal parameters of a $100 \mathrm{~kW}$ SOFC stack operated at $1273 \mathrm{~K}$; the obtained parameters are tabulated in Table 7 in comparison to those obtained by the others. Regarding the obtained results, the proposed EO outperformed the others, achieving the minimum SMSE with a value of 1.0406. MRFO comes in the second rank with a fitness function of 1.0775, and then CLDMMPA achieves an SMSE of 1.3204 and comes in the third rank. Figure 7 shows the measured and calculated polarization curves obtained via the EO, and both curves are closely converged. However, Figure 8 shows the polarization curves obtained via MPA, HBO, SOA, and MRFO. The statistical parameters of all optimizers in such cases 
are calculated and tabulated in Table 8 , where the best parameters are obtained by the proposed EO. Figure 9 shows the performance of each optimizer during implementing the iterative process. The performance of the proposed EO is confirmed to be better than the others.

Table 6. SOFC stack specifications [30,31].

\begin{tabular}{cc}
\hline Parameter & Value \\
\hline$P_{\text {rated }}(\mathrm{W})$ & $100 \mathrm{~kW}$ \\
$n_{c}$ & 384 \\
$E_{0}(\mathrm{~V})$ & 1.18 \\
$T(\mathrm{~K})$ & 1273 \\
$K_{\mathrm{H}_{2}}(\mathrm{kmol} / \mathrm{s} / \mathrm{atm})$ & $8.43 \times 10^{-4}$ \\
$K_{\mathrm{O}_{2}}(\mathrm{kmol} / \mathrm{s} / \mathrm{atm})$ & $2.52 \times 10^{-3}$ \\
$K_{\mathrm{H}_{2} \mathrm{O}}(\mathrm{kmol} / \mathrm{s} / \mathrm{atm})$ & $2.81 \times 10^{-4}$ \\
$\mathrm{r}_{\mathrm{H}-\mathrm{O}}$ & 1.145 \\
$\tau_{\mathrm{H}_{2}}(\mathrm{~s})$ & 26.1 \\
$\tau_{\mathrm{O}_{2}}(\mathrm{~s})$ & 2.91 \\
$\tau_{\mathrm{H}_{2} \mathrm{O}}(\mathrm{s})$ & 78.3 \\
$\mathrm{~T}_{\mathrm{e}}(\mathrm{s})$ & 0.8 \\
\hline
\end{tabular}

Table 7. The optimal parameters of SOFC dynamic-state based model operated at $1273 \mathrm{~K}$.

\begin{tabular}{ccccccc}
\hline & $\begin{array}{c}\text { CLDMMPA } \\
\text { [20] }\end{array}$ & MPA & HBO & SOA & MRFO & $\begin{array}{c}\text { The Proposed } \\
\text { EO }\end{array}$ \\
\hline$E_{0}(\mathrm{~V})$ & 1.1405 & 1.199847 & 1.194939 & 0.89461271 & 1.113337 & 1.144398 \\
$a(\mathrm{~V})$ & 0.037449 & 0.04882335 & 0.04756176 & 0.000 & 0.02729001 & 0.02982692 \\
$J_{o}\left(\mathrm{~A} / \mathrm{cm}^{2}\right)$ & 0.095442 & 0.09987029 & 0.0939504 & 0.090655585 & 0.03143729 & 0.0202932 \\
$r\left(\mathrm{k} \Omega \cdot \mathrm{cm}^{2}\right)$ & 0.0001829 & $4.3684 \times 10^{-5}$ & $4.873756 \times 10^{-5}$ & 0.000 & 0.0002672047 & 0.0002547476 \\
$b(\mathrm{~V})$ & 0.10386 & 0.1551425 & 0.1515045 & 0.32672895 & 0.08200661 & 0.08350225 \\
$J_{\max }\left(\mathrm{A} / \mathrm{cm}^{2}\right)$ & 0.8367 & 865.6602 & 859.6317 & 1000 & 825.4696 & 825.7578 \\
Elapsed time & $\mathrm{NA}$ & 433.946266 & 331.304354 & 222.830499 & 593.725886 & 327.35802 \\
$(\mathrm{sec})$ & 1.3204 & 3.0887 & 3.3486 & 34.1692 & 1.0775 & 1.0406 \\
SMSE & & & & & &
\end{tabular}

Table 8. Statistical parameters (best, worst, mean, median, variance, and standard deviation) of all optimizers used for dynamic-state SOFC model.

\begin{tabular}{ccccccc}
\hline & CLDMMPA [20] & MPA & HBO & SOA & MRFO & The Proposed EO \\
\hline Best & 1.3204 & 3.08867 & 3.3486 & 34.1692 & 1.0775 & 1.04061 \\
Worst & 3.9835 & 25.1135 & 10.473 & 5401.8725 & 3.4164 & 2.00140 \\
Mean & 3.2462 & 8.54964 & 5.6209 & 1025.8099 & 1.7115 & 1.1352 \\
Median & 3.5241 & 6.07593 & 4.8835 & 34.3473 & 4.5141 & 1.0816 \\
Variance & 0.51027 & 36.3547 & 2.7528 & $3,915,661.957$ & 0.23360 & 0.02264 \\
Std. deviation & 0.71434 & 6.02948 & 1.6592 & 1978.803 & 0.15284 & 0.15048 \\
\hline
\end{tabular}

After identifying the parameters of the transient-state based model of SOFC, the model of fuel cell is implemented in Simulink/Matlab, and two load disturbances are applied to the model. The first disturbance is shown in Figure 10 (1st graph), the power is changed from $30 \mathrm{~kW}$ to $60 \mathrm{~kW}$ at a time of $300 \mathrm{sec}$., and given the identified parameters via the proposed EO and the stack output power plotted with the load disturbance, it is clear that they are closely matched, this means that the EO succeeded in extracting the correct parameters of the SOFC dynamic model. Moreover, the load current of the constructed model is closely converged to the disturbance current (3rd graph, Figure 10). Moreover, the terminal voltage (2nd graph) and the voltage drops occur inside the stack (4th graph), and they are shown in Figure 10. The constructed model via the proposed EO succeeded in tracking the changes in the load power. Moreover, a second disturbance is applied on 
the dynamic model in which the load power has two variations; as shown in Figure 11 (1st graph), the load power changes from $20 \mathrm{~kW}$ to $40 \mathrm{~kW}$ at $200 \mathrm{~s}$ and then changes again to $60 \mathrm{~kW}$ at $400 \mathrm{~s}$ on the same graph. The output power from the constructed model with identified parameters via the proposed EO is given, and both curves are converged. The terminal voltage, the corresponding current, and the voltage drops are shown in Figure 11 (2nd graph, 3rd graph, and 4th graph, respectively).

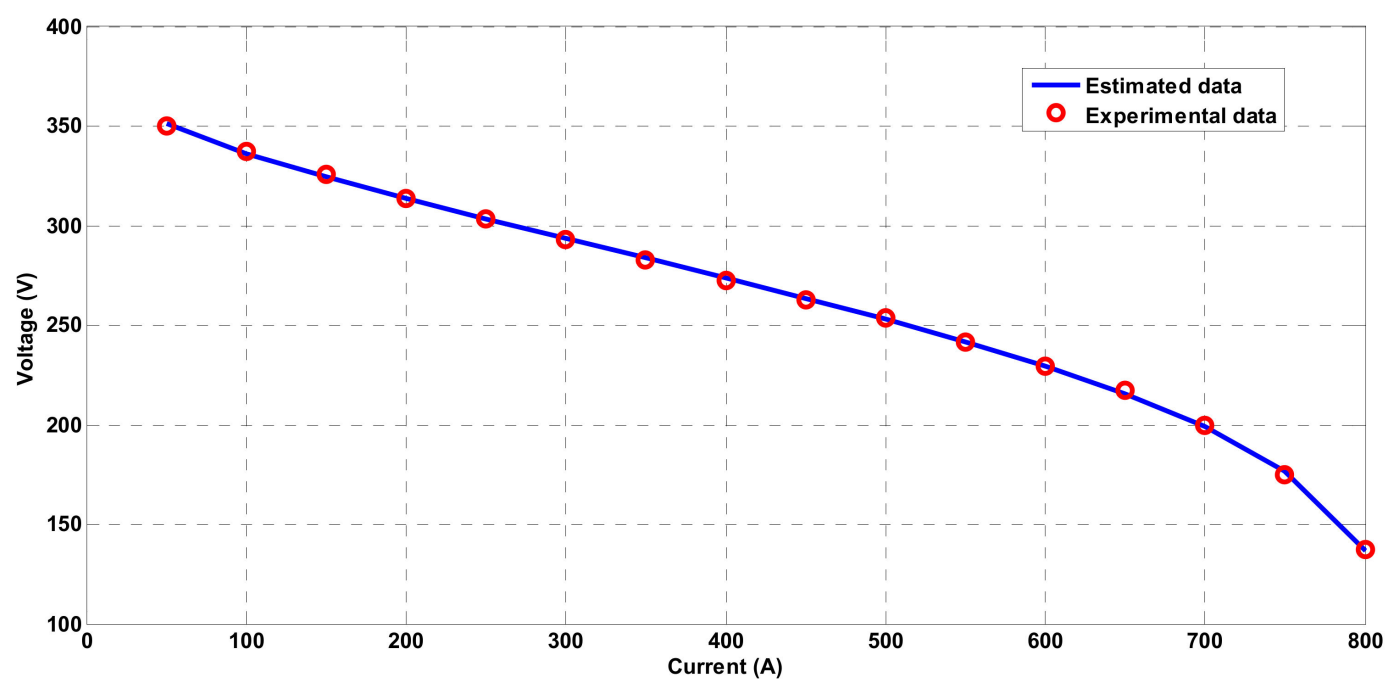

(a)

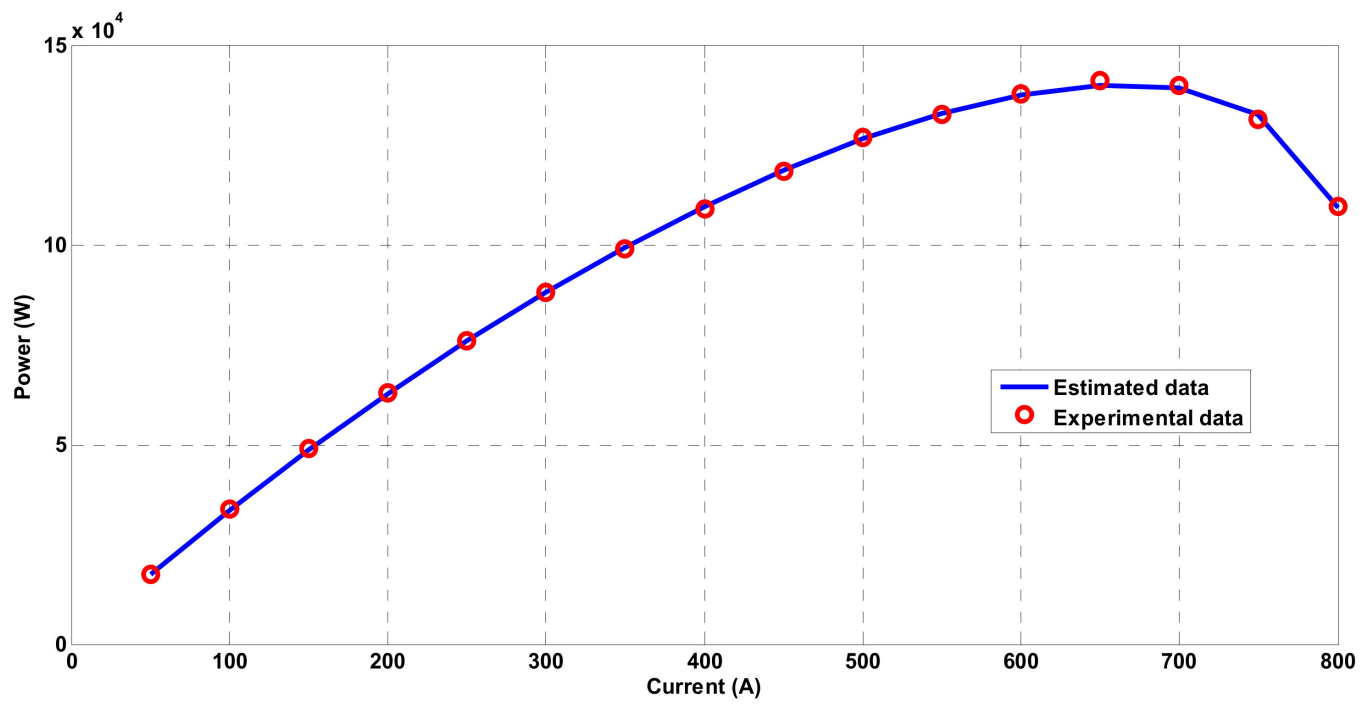

(b)

Figure 7. The measured and calculated polarization curves of SOFC dynamic-state model operated at $1273 \mathrm{~K}$ obtained via EO (a) current-voltage, (b) current-power.

Finally, it can be concluded that the proposed methodology incorporating the EO is reliable, superior, and efficient over other employed approaches in constructing a reliable model of the SOFC-based model operated under either steady-state or dynamicstate modes. 


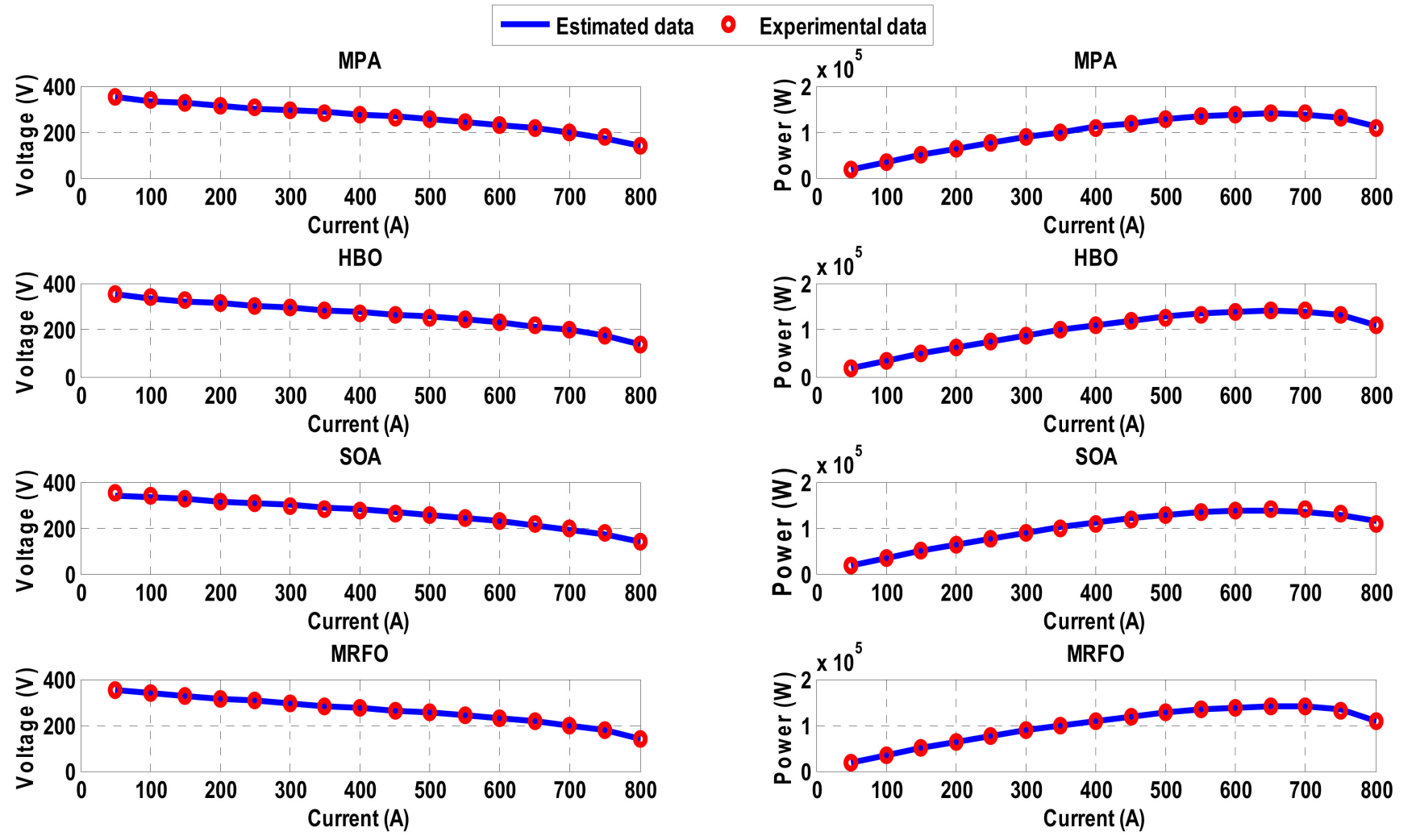

Figure 8. The measured and calculated polarization curves of SOFC dynamic-state model operated at $1273 \mathrm{~K}$ obtained via MPA, HBO, SOA, and MRFO.

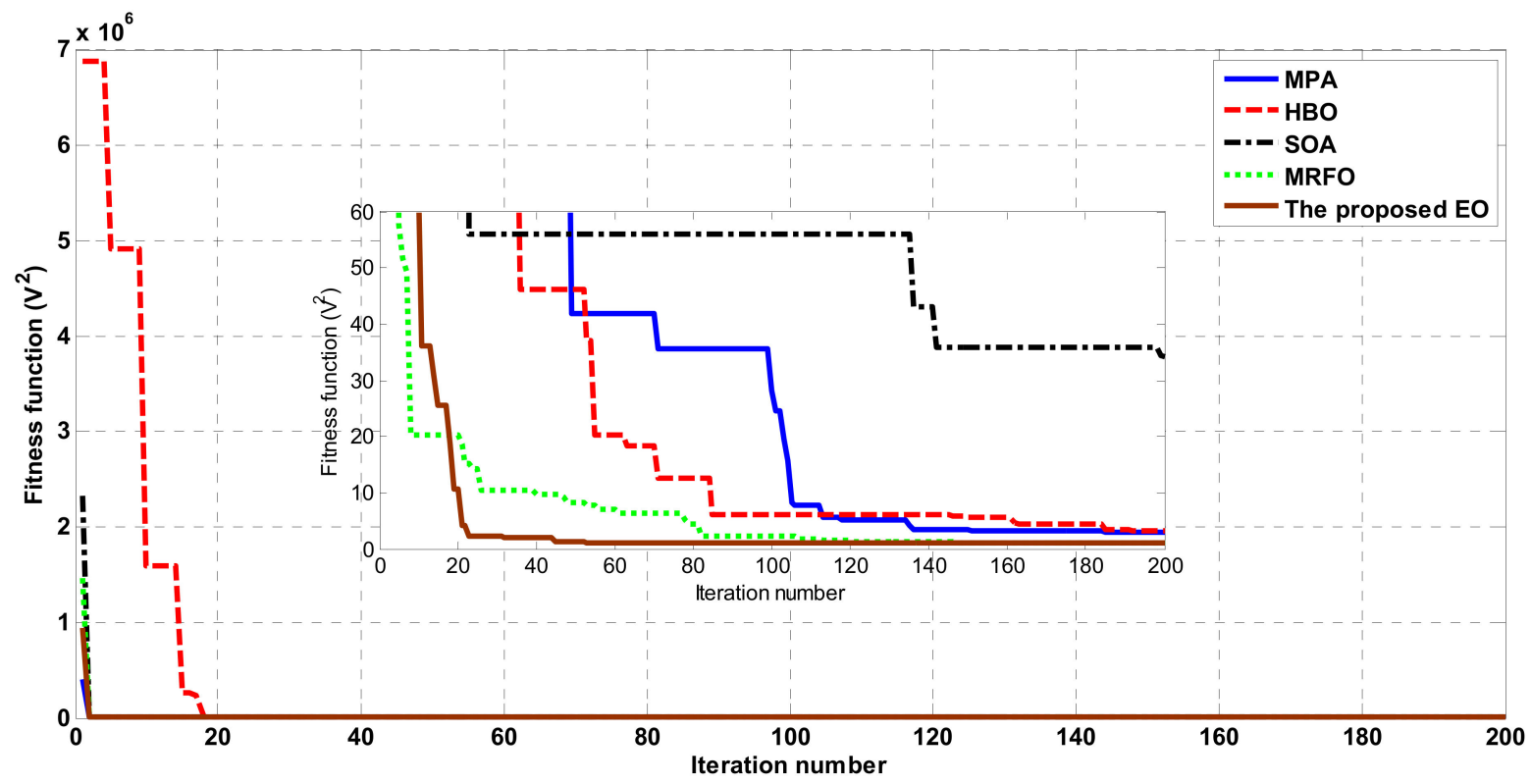

Figure 9. The variation of fitness function during iterative process for all employed optimizers applied for dynamic-state SOFC model. 

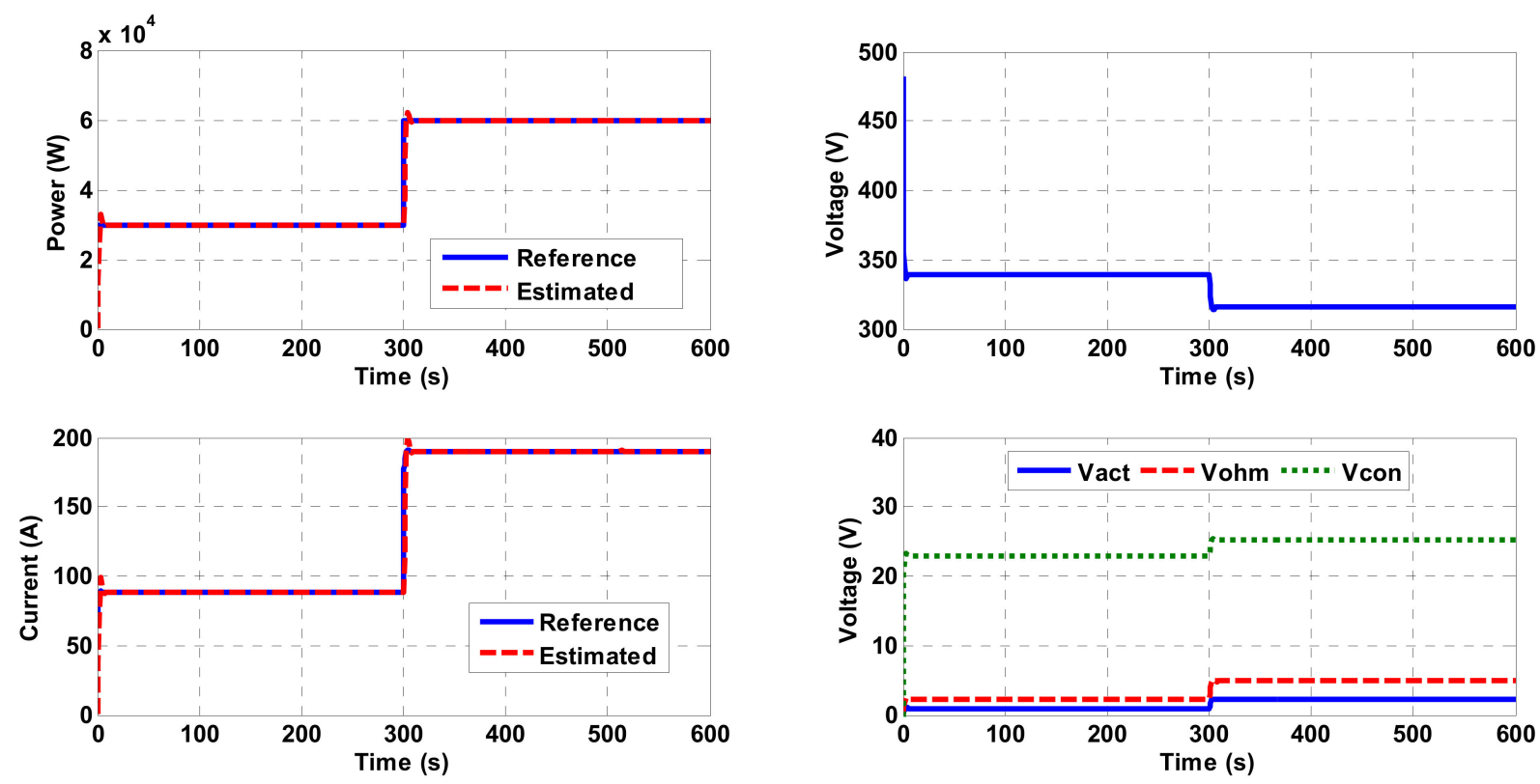

Figure 10. First load disturbance applied on SOFC stack dynamic model.
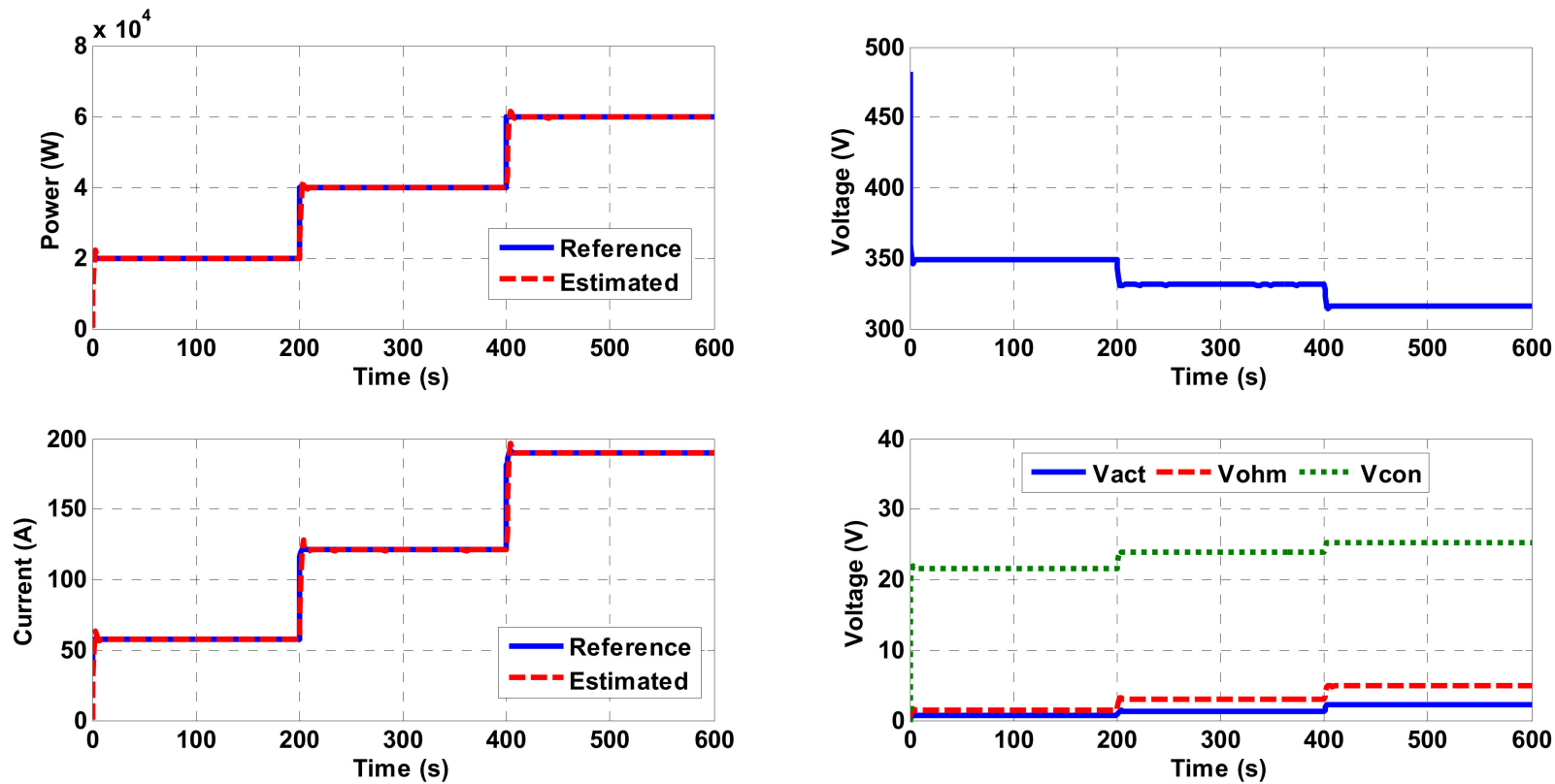

Figure 11. Second load disturbance applied on SOFC stack dynamic model.

\section{Conclusions}

This work introduces a new methodology based on a new metaheuristic approach named equilibrium optimizer (EO) to estimate the optimal parameters of a solid oxide fuel cell (SOFC) model. This is achieved with the aid of experimental datasets of the fuel cell polarization curves. The sum squared error difference between the cell experimental and computed voltages is selected as the fitness function to be minimized. The work investigates two operating modes of FC, which are steady- and dynamic-states models under altering operating conditions. In the first model, the parameters are estimated at four temperatures via the recorded measured polarization curves at them. In the dynamic model, two load power disturbances are investigated after identifying the parameters via the proposed EO. The obtained results via the proposed EO are compared to those obtained by the Archimedes optimization algorithm (AOA), Heap-based optimizer (HBO), Seagull Optimization Algorithm (SOA), Student Psychology Based Optimization 
Algorithm (SPBO), Marine predator algorithm (MPA), Manta ray foraging optimization (MRFO), and comprehensive learning dynamic multi-swarm marine predators algorithm. In the case of the SOFC steady-state model, the proposed EO succeeded in achieving the best (minimum) fitness function of $2.6906 \times 10^{-6}, 1.5527 \times 10^{-6}, 2.6809 \times 10^{-6}$, and $2.2995 \times 10^{-6}$ at operating temperature of $1073 \mathrm{~K}, 1173 \mathrm{~K}, 1213 \mathrm{~K}$, and $1273 \mathrm{~K}$, respectively. The corresponding standard deviations in the four studied cases obtained via the proposed EO are $9.15673 \times 10^{-7}, 1.63132 \times 10^{-6}, 3.36081 \times 10^{-6}$, and $2.2119 \times 10^{-6}$. Regarding the obtained results of the SOFC dynamic-state model, the proposed EO outperformed the others, achieving the minimum SMSE with a value of 1.0406; the MRFO comes in the second rank with a fitness function of 1.0775, and then the CLDMMPA achieves a SMSE of 1.3204 and comes in the third rank. The proposed EO succeeded in achieving a variance of 0.02264 and a standard deviation of 0.15048 in this studied case. The findings of this study demonstrate the superiority and reliability of the proposed approach in constructing a good-performance model that converges to the real one.

Author Contributions: All authors collaborated and contributed equally to this work. All authors have read and agreed to the published version of the manuscript.

Funding: This research received funding from the Institutional Fund Projects under grant no. (IFPHI173-135-2020) supported by the Ministry of Education and King Abdulaziz University, Deanship of Scientific Research (DSR), Jeddah, Saudi Arabia.

Acknowledgments: This research work was funded by the Institutional Fund Projects under grant no. (IFPHI-173-135-2020). Therefore, authors gratefully acknowledge technical and financial support from the Ministry of Education and King Abdulaziz University, DSR, Jeddah, Saudi Arabia.

Conflicts of Interest: The authors declare no conflict of interest.

\section{References}

1. Capodaglio, A.G.; Cecconet, D.; Molognoni, D. An integrated mathematical model of microbial fuel cell processes: Bioelectrochemical and microbiologic aspects. Processes 2017, 5, 73. [CrossRef]

2. Bizon, N.; Thounthong, P. Energy efficiency and fuel economy of a fuel cell/renewable energy sources hybrid power system with the load-following control of the fueling regulators. Mathematics 2020, 8, 151. [CrossRef]

3. Wilberforce, T.; El-Hassan, Z.; Khatib, F.; Al Makky, A.; Baroutaji, A.; Carton, J.G.; Olabi, A.G. Developments of electric cars and fuel cell hydrogen electric cars. Int. J. Hydrogen Energy 2017, 42, 25695-25734. [CrossRef]

4. El-Hay, E.A.; El-Hameed, M.A.; El-Fergany, A.A. Performance enhancement of autonomous system comprising proton exchange membrane fuel cells and switched reluctance motor. Energy 2018, 163, 699-711. [CrossRef]

5. Rokni, M. Addressing fuel recycling in solid oxide fuel cell systems fed by alternative fuels. Energy 2017, 137, 1013-1025. [CrossRef]

6. Olabi, A. Renewable energy and energy storage systems. Energy 2017, 136, 1-6. [CrossRef]

7. Ramadhani, F.; Hussain, M.; Mokhlis, H.; Hajimolana, S. Optimization strategies for Solid Oxide Fuel Cell (SOFC) application: A literature survey. Renew. Sustain. Energy Rev. 2017, 76, 460-484. [CrossRef]

8. Chowdhury, S.; Chowdhury, S.P.; Crossley, P. Microgrids and Active Distribution Networks; The Institution of Engineering and Technology: London, UK, 2009.

9. El-Hay, E.; El-Hameed, M.; El-Fergany, A. Steady-state and dynamic models of solid oxide fuel cells based on Satin Bowerbird Optimizer. Int. J. Hydrogen Energy 2018, 43, 14751-14761. [CrossRef]

10. El-Hay, E.; El-Hameed, M.; El-Fergany, A. Optimized parameters of SOFC for steady state and transient simulations using interior search algorithm. Energy 2019, 166, 451-461. [CrossRef]

11. Van Biert, L.; Godjevac, M.; Visser, K.; Aravind, P. Dynamic modelling of a direct internal reforming solid oxide fuel cell stack based on single cell experiments. Appl. Energy 2019, 250, 976-990. [CrossRef]

12. Gong, W.; Yan, X.; Hu, C.; Wang, L.; Gao, L. Fast and accurate parameter extraction for different types of fuel cells with decomposition and nature-inspired optimization method. Energy Convers. Manag. 2018, 174, 913-921. [CrossRef]

13. Ettihir, K.; Boulon, L.; Becherif, M.; Agbossou, K.; Ramadan, H. Online identification of semi-empirical model parameters for PEMFCs. Int. J. Hydrogen Energy 2014, 39, 21165-21176. [CrossRef]

14. Ang, S.M.C.; Brett, D.J.; Fraga, E.S. A multi-objective optimisation model for a general polymer electrolyte membrane fuel cell system. J. Power Sources 2010, 195, 2754-2763. [CrossRef]

15. Tahmasbi, A.A.; Hoseini, A.; Roshandel, R. A new approach to multi-objective optimisation method in PEM fuel cell. Int. J. Sustain. Energy 2013, 34, 283-297. [CrossRef] 
16. Petrescu, S.; Petre, C.; Costea, M.; Malancioiu, O.; Boriaru, N.; Dobrovicescu, A.; Feidt, M.; Harman, C.; Stanciu, C. A methodology of computation, design and optimization of solar Stirling power plant using hydrogen/oxygen fuel cells. Energy 2010, 35, 729-739. [CrossRef]

17. Virkar, A.; Williams, M.C.; Singhal, S. Concepts for ultra-high power density solid oxide fuel cells. ECS Trans. 2007, 5, 401-421. [CrossRef]

18. Zhu, L.; Zhang, L.; Virkar, A.V. A parametric model for solid oxide fuel cells based on measurements made on cell materials and components. J. Power Sources 2015, 291, 138-155. [CrossRef]

19. Shi, H.; Li, J.; Zafetti, N. New optimized technique for unknown parameters selection of SOFC using Converged Grass Fibrous Root Optimization Algorithm. Energy Rep. 2020, 6, 1428-1437. [CrossRef]

20. Yousri, D.; Hasanien, H.M.; Fathy, A. Parameters identification of solid oxide fuel cell for static and dynamic simulation using comprehensive learning dynamic multi-swarm marine predators algorithm. Energy Convers. Manag. 2021, 228, 113692. [CrossRef]

21. Nassef, A.M.; Fathy, A.; Sayed, E.T.; Abdelkareem, M.A.; Rezk, H.; Tanveer, W.H.; Olabi, A. Maximizing SOFC performance through optimal parameters identification by modern optimization algorithms. Renew. Energy 2019, 138, 458-464. [CrossRef]

22. Fathy, A.; Rezk, H.; Ramadan, H.S.M. Recent moth-flame optimizer for enhanced solid oxide fuel cell output power via optimal parameters extraction process. Energy 2020, 207, 118326. [CrossRef]

23. Wang, X.; Huang, B.; Chen, T. Data-driven predictive control for solid oxide fuel cells. J. Process. Control 2007, 17, 103-114. [CrossRef]

24. Larminie, J.; Dicks, A.; McDonald, M.S. Fuel Cell Systems Explained; John Wiley \& Sons: Chichester, UK, 2003 ; Volume 2.

25. Faramarzi, A.; Heidarinejad, M.; Stephens, B.; Mirjalili, S. Equilibrium optimizer: A novel optimization algorithm. Knowl. Based Syst. 2020, 191, 105190. [CrossRef]

26. Wei, Z.; Zou, C.; Leng, F.; Soong, B.H.; Tseng, K.-J. Online model identification and state-of-charge estimate for lithium-ion battery with a recursive total least squares-based observer. IEEE Trans. Ind. Electron. 2018, 65, 1336-1346. [CrossRef]

27. Wei, Z.; Zhao, J.; Xiong, R.; Dong, G.; Pou, J.; Tseng, K.J. Online estimation of power capacity with noise effect attenuation for lithium-ion battery. IEEE Trans. Ind. Electron. 2019, 66, 5724-5735. [CrossRef]

28. Wei, Z.; Zhao, D.; He, H.; Cao, W.; Dong, G. A noise-tolerant model parameterization method for lithium-ion battery management system. Appl. Energy 2020, 268, 114932. [CrossRef]

29. Wei, Z.; Meng, S.; Xiong, B.; Ji, D.; Tseng, K.J. Enhanced online model identification and state of charge estimation for lithium-ion battery with a FBCRLS based observer. Appl. Energy 2016, 181, 332-341. [CrossRef]

30. Pierre, J. Siemens energy. In Proceedings of the 11th Annual SECA Workshop, Pittsburgh, PA, USA, 27-29 July 2010.

31. Xu, D.; Jiang, B.; Liu, F. Improved data driven model free adaptive constrained control for a solid oxide fuel cell. IET Control. Theory Appl. 2016, 10, 1412-1419. [CrossRef] 